CUPAUAM. 19-1992, 361-398

\title{
"LOS PLATOS DE GERASA (I): DECORACIONES E ICONOGRAFIA"
}

\author{
AleXANDRA UsCaTESCU BARRON
}

\section{Resumen}

En este artículo se determina la producción de una serie de platos de origen geraseno y cronología bizantina (siglo VI e inicios del siglo VII d.C.), cuyas formas se inspiran en ciertos modelos de terra sigillata africana, focense y chipriota tardias. Su centro de producción, actualmente, se debe localizar en el yacimiento de origen helenístico de Gerasa (Ŷarašs, Jordania).

Estos platos, a pesar de inspirarse en ciertas importaciones occidentales y orientales bizantinas, desarrollan una serie de decoraciones pintadas, incisas e impresas propias, inspiradas, fundamentalmente en dos corrientes iconográficas tardías: cristiana y pagana.

\section{Summary}

This paper states the production of a bowl series of gerasian origin and byzantine chronology ( 6 th and early 7 th centuries A.D.). Their shapes are inspired by certain forms of African, Phocaean and Cypriot $D$ Red Slip Wares. The Hellenistic origin site of Gerasa (Jarash, Jordan) could be considered as the main production centre.

These plates although are inspired by certain western and eastern Byzantine imported wares, they develop a series of painted, incised and stamped decorations. They are inspired, basecly, by two late iconographic trends: Christian and Pagan.

\section{1.- INTRODUCCION}

\section{1.- Definición de los platos de Gerasa.}

Los denominados platos de Gerasa (1) son una producción cerámica bizantina (siglo VI e inicios del VII d.C.) originaria de esta ciudad jordana, la actual Ŷaras.

(1) Todas las piezas que aquí presentamos fueron exhumadas durante las excavaciones realizadas por la Misión Arqueológica Espańola en el Macellum de Gerasa. Excavaciones dirigidas por el Dr. Martín Bueno de la universidad de Zaragoza, a quien... aprovechando estas líneas queremos agradecer las facilidades concedidas para el estudio de estas piezas cerámicas en el mismo yacimiento de $\hat{Y}$ aras. 
Esta producción aunque conocida desde la década de los años treinta (Fisher y McCown 1931,36. Pl.14), no fue correctamente identificada hasta hace pocos años cuando fue publicada bajo la denominación de "Jerash Bowls" (Montlivault 1986,71; Gawlikowski 1986,107; Gawlikowski y Musa 1986,147; Watson 1989,223-262; Uscatescu 1993,190-269).

Una de las primeras descripciones que conocemos sobre esta producción local es la de P. Watson (Ball, Bowsher, Kehrberg, Walmsley y Watson 1986,365) en la que ya se definen las características distintivas de estas cerámicas: su decoración pintada figurada, a la que M. Gawlikowski añade las decoraciones estampilladas (Gawlikowski 1986,118).

\section{2.- Marco cronológico y geográfico de los platos de Gerasa}

Actualmente se puede afirmar, sin ningún tipo de dudas que los platos de Gerasa son una producción local de época tardobizantina (2); es decir, que florecen, por lo menos, a inicios del siglo VI d.C. y perduran hasta la primera mitad del siglo VII d.C., fecha de la conquista islámica de la antigua provincia de Arabia. Por las pruebas arqueológicas que aportamos más adelante, actualmente no se puede sostener la tesis de J.H. Iliffe, él cual describió los platos de Gerasa como una producción árabe (Iliffe 1945,1) ni tampoco la solución intermedia que propuso M. Gawlikowski, autor que sostuvo que se trataba de una producción bizantino-omeya (HomésFredericq y Franken 1985,225).

Las pruebas arqueológicas que avalan la cronología propuesta para estas cerámicas son de índole estratigráfica fundamentalmente. En primer lugar, en Gerasa aparecen siempre en contextos del siglo VI e inicios del VII d.C. Los ejemplos más tempranos del yacimiento de Gerasa proceden de la zona del Tetrapylon Norte, de la fase 6, de principios del siglo VI d.C. (Watson 1989,237$)$ y en la Puerta Sur de esta ciudad, donde se fechan en depósitos de la primera mitad del siglo VI d.C. (Montlivault 1986,71). A mediados del siglo VI d.C. continuan documentándose en la capa 3 de una cisterna del Santuario de Zeus de Gerasa (Rasson y Seigne 1989,150) y también en los depósitos de la fase 7 del Tetrapylon Norte, del último cuarto de ese siglo (Ball, Bowsher, Kehrberg, Walmsley y Watson 1986,365). En el Macellum de Gerasa las únicas pruebas estratigráficas seguras y fiables para datar esta producción proceden de niveles de finales del siglo VI d.C. (niveles de destrucción de las tabernas 11 y 15 del mercado).

Los últimos platos de Gerasa se fechan en el primer cuarto del siglo VII d.C.; en las excavaciones del equipo australiano los hay en depósitos con monedas posteriores a Justino II. En la zona de la casa omeya del Decumanus Sur, según M. Gawlikowski, los platos de Gerasa aparecen en depósitos inmediatamente anteriores a la construcción de época omeya (Homés-Fredericq y Franken 1985,224). Y por último, las excavaciones del Macellum también corroboran esta afirmación, ya que aparecen junto con un follis de Focas del 604-610 d.C. (3) en el nivel de destrucción de inicios del siglo VII d.C. de una de las exedrae de este edificio.

(2) El término tardobizantino se entiende para el caso concreto de la región jordana. Para ello hemos seguido la clasificación cronológica de J.A. Sauer propuesta para el yacimiento de Esbus (Sauer 1973). Cronológicamente iría desde la subida al poder de Anastasio I (491 d.C.) a la conquista de la zona por los Califas Ortodoxos, en general, en el año 640 d.C.

(3) Las monedas de las excavaciones del Macellum de Gerasa están siendo estudiadas, en forma de tesis doctoral, por T. Marot Salsas, técnico del Gabinete Numismático de Cataluña. 
El ejemplo más temprano de estas cerámicas, fuera de Gerasa, es el de la fortaleza de Laŷŷūn en el sur de Jordania (Parker 1987,544), fechado a inicios del siglo VI d.C., anterior, por lo tanto, al terremoto del 551 d.C. Sin embargo, en Pella no aparecen en la fase II, que corresponde a niveles del primer cuarto del siglo VI d.C.; en la siguiente fase IIIa de Pella, del segundo cuarto del siglo VI d.C., tan sólo hay una pieza. En la fase IIIb, del tercer cuarto del siglo VI d.C., el número de platos de Gerasa se incrementa, y en el último cuarto del siglo VI, en la fase IV de Pella, son abundantes. En la fase V (ca. 600-633 d.C., antes del terremoto del 633 d.C.) decae el número de piezas y comienza a señalarse el final de la producción (Watson 1989,238) y de su comercialización.

En Monte Nebo, yacimiento fundamentalmente bizantino, existe una serie de platos decorados que, quizá, se puedan identificar con platos de Gerasa por su decoración. H. Schneider $(1950,60)$ menciona cruces de Malta pintadas en alguno de ellos. Estos hallazgos de Nebo se sitúan en el siglo VI d. c. (Schneider 1950,65).

En Dibān hemos detectado una forma que quizá pueda corresponder a un plato de Gerasa y que se fecha en el segundo cuarto del siglo VI d.C. (Tushingham 1972. Fig.11,38).

Desde la definición de los platos de Gerasa como producción homogénea, su zona de aparición se ha ido ampliando, y no sólo se conocen en Gerasa, donde son muy abundantes, sino también en otras zonas del centro-norte de Jordania y sur de Siria (fig.1), como Monte Nebo (Schneider 1950,66. Fig.6,5), en la fortaleza de Laŷŷūn (Parker 1987,544. Fig.121,225); en antiguas ciudades de la Decápolis como Scythopolis (Bait-San), Abila (Tall Abil), Pella (Tabaqat Faḅl) o Philadelphia (Ammán), en Cafarnaúm, en Boșrā, en Umm al-Ŷimal, en Jirbat al-Samrā, en Qașr alfHalläbāt, en Umm al-Rașạs (Watson 1989,233-234), en Dibān (Winnett y Reed 1964,72. Pl.66,10); Tushingham 1972. Fig.11,38), Bethania (Saller 1957,265-266. Fig.50,2421), yacimientos situados, fundamentalmente a lo largo de la Via Nova Traiana y, posiblemente, en Palmyra (Michalowski 1962,212. Fig.240).

\section{3.- Origen de los platos de Gerasa}

Las formas de los platos de Gerasa recuerdan en algunos casos a ciertas formas de cerámicas importadas, por ello no es extraño encontrar esta producción descrita como terra sigiIlata africana: "...some dishes of ARS (terra sigillata africana) 105 Hayes form, which however present a characteristic over painted decoration..." (Pierobon 1986,185) o como imitaciones de terra sigillata focense tardia ("Late Roman C" o "Phocaean Red Slip Ware") según A-M. Rasson : "...ces assiettes empruntent leurs formes à la céramique dite Late Roman C: assiettes à base annulaire, panse plus ou moins droite, et une grande diversité dans les lèvres;..." (Rasson 1987,63).

La clarificación de este grupo cerámico, con la publicación de uno de los primeros trabajos de carácter más científico, se realiza a finales de la decáda de los años ochenta (Duerden y Watson 1988). En esta obra se demostró, por análisis de pastas cerámicas, la diferencia con respecto a las producciones africanas, en las cuales se inspiran, en parte, los platos de Gerasa.

Ciertamente, la inspiración de los platos de Gerasa en ciertos modelos importados es innegable; algunas formas recuerdan a la terra sigillata africana, formas 93A, 99, 101, 104 y 105 de Hayes, otras a la terra sigillata focense tardia. Hayes 1,3 y 9 , y en menor medida, a la sigillata chipriota tardia, forma 9 de Hayes, prototipos que se pueden fechar, al igual que los platos de Gerasa, entre el siglo VI d.C. e inicios del VII d.C. 
Las causas del fenómeno de creación de esta producción local gerasena no están bien definidas. Su creación no resulta extraña ya que la producción de cerámicas finas locales se puede remontar al siglo I a.C. o I d.C. (Braemer 1989), por un lado y, por otro, es algo aceptado que la industria alfarera bizantina alcanza un alto grado de industrialización en el siglo VI d.C. (Homés-Fredericq y Franken 1985,231-232), una industria que no sólo fue capaz de satisfacer la autodemanda, sino que también exportó sus productos a otras ciudades de la región, como Pella (Walmsley 1988,153) o Lâŷyun. Y aunque no debemos olvidar que a Gerasa llegaron piezas importadas del norte de Africa y de Asia Menor, estas siempre aparecen en proporciones (en los niveles estudiados en el Macellum) mucho menores que las producciones locales, en concreto, que los platos de Gerasa, siempre más numerosos en los niveles del siglo VI d.C.

\section{4.- Características generales}

En cuanto a las formas se puede decir que, en general, son platos o cuencos abiertos de borde simple, almendrado o plano, exvasado, con perfiles hemisféricos o troncocónicos de paredes abiertas, con una base característica de pie anular alto.

La calidad de las pastas varía ligeramente pero, en general, se trata de pastas muy depuradas de aspecto granuloso, con fractura recta y angulosa. El desgrasante más abundante a simple vista es el calcáreo, que parece característico de las arcillas de esta zona. La pasta es, con pequeñas diferencias en su calidad, muy semejante a la empleada en la fabricación de otros tipos de la cerámica común local.

En el lote del Macellum de Gerasa hemos localizado tres tipos de pastas. Esta diferenciación es puramente visual, ya que tras los análisis de fluorescencia de rayos " $\mathrm{X}$ " realizados por la Misión Arqueológica Española (4) (Uscatescu 1993,955-956), se demostró que estos distintos tipos de pastas tenían una composición química semejante, al menos el primer y el tercer tipo. Estos tipos serían:

a) Pasta de tonalidad naranja (Cailleux P 40/N 40), de aspecto granuloso en fractura, con engobe del mismo color, no muy espeso y de acabado mate, a veces se detecta en los bordes y paredes de las piezas un espatulado. En ocasiones se advierten núcleos grises en fractura. Esta pasta aparece en los platos de Gerasa pintados sobre el mismo engobe anaranjado y en los incisos con estampilla central.

$\beta$ ) Pasta de color ocre, muy depurada, con engobe también del mismo tono. La cocción es habitualmente irregular ya que presenta núcleos grises en fractura. Aparece en los platos de Gerasa decorados con ruedecilla y pintados.

$\gamma)$ Pasta anaranjada, muy granulosa con abundantes desgrasantes calcáreos observables a simple vista, las cocciones irregulares no son raras. El engobe, grueso, es de color blanco de aspecto mate. Aparece en los denominados platos de Gerasa de engobe blanco decorados exclusivamente con motivos pintados en rojo.

En lo referente a las cocciones, en términos generales, son oxidantes y bastante regulares, el $78 \%$ de los platos de Gerasa (5) muestra este tipo de cocción. Pero hay que reconocer que la

(4) Estos análisis fueron realizados por J. Buxeda y A. Sagristá en la Universidad Central de Barcelona.

(5) Este porcentaje se refiere al número total de platos de Gerasa incluido en el capítulo dedicado a los platos de Gerasa en nuestra tesis doctoral (Uscatescu 1993), de 449 fragmentos. 
información que tenemos es limitada, ya que en la mayoría de los casos sólo contamos con fragmentos, y al carecer de formas completas no se puede afirmar taxativamente la regularidad de esta cocción oxidante y, además, las cocciones alternas no están ausentes en estas producciones.

\section{2.- DECORACIONES DE LOS PLATOS DE GERASA}

Aunque P. Watson, investigadora especializada en la producción de los platos de Gerasa $(1989,229)$ sólo distingue dos tipos de decoración: pintada y estampillada, dentro del corpus del Macellum se han registrado muchos más tipos de decoración:

* Decoración pintada: $\quad$ - sobre engobe blanco.

- sobre engobe naranja.

- sobre círculo central blanco.

* Decoración estampillada: - estampillada simple.

- círculos concéntricos incisos y

* Decoración incisa.

* Decoraciones mixtas: - incisa e impresa a ruedecilla.

- incisa y pintada.

- pintada, incisa e impresa a ruedecilla.

\section{1.- La decoración pintada}

Este tipo de decoración es el más abundante, y fue el que determinó su propia definición como producción cerámica local, distinta a la terra sigillata importada.

Fundamentalmente se emplean dos colores: el blanco y el rojo de tonalidades oscuras y vinosas. El color del soporte es lo que determina la clasificación de esta decoración en tres variantes: pintada en rojo sobre engobe o cubierta blanca, pintada en blanco y rojo sobre engobe anaranjado y pintada en rojo sobre círculo blanco.

En cuanto a la técnica empleada en los tres casos es siempre la misma: la pintura se aplica sobre el soporte rápidamente con un pincel, por lo que su absorción en la pasta no es muy fuerte, no es una unión muy cohesiva, y esta decoración pintada a veces se pierde (Franken y Kalsbeek 1975,51).

Los motivos decorativos, siempre dispuestos en el interior de la pieza en una posición central a excepción de una pieza (fig.4,16), se pueden dividir en principales y secundarios. Los principales son los que presentan una mayor variedad. Se pueden dividir, a su vez, en geométricos y figurativos. Estos últimos van desde figuras aisladas a la composición de escenas o motivos simbólicos. En cuanto a los motivos pintados secundarios son menos variados, el repertorio se reduce a los del tipo geométrico y vegetal. Los primeros se sitúan casi siempre cercanos al borde o rodeando a la figura central; el motivo secundario vegetal más abundante es el que recuerda a unas orlas de pámpanos estilizados (fig.9,46).

\section{a) Platos de Gerasa pintados, con engobe blanco}

Se caracterizan por un engobe espeso, de color blanco, que se realiza por inmersión total o parcial del vaso. Se trata simplemente, de una pintura blanca más espesa que se adhiere a la pasta con poca cohesión, ya que este engobe suele desaparecer o perder espesor con un simple lavado con agua. Las decoraciones son siempre pintadas en color rojo. 
Los platos de Gerasa de engobe blanco fueron definidos por P. Watson como "formato o esquema 3" (Watson 1989,231) y aunque son difíciles de clasificar cronológicamente, parece que existe una afinidad en la composición química de esta variedad con los platos más corrientes de engobe anaranjado o rojizo y decoración pintada en rojo y blanco, por lo que esta similitud de los componentes de la pasta indica, simplemente, un esquema decorativo distinto, pero contemporáneo, al menos desde finales del siglo VI d.C. e inicios del VII d.C. (Duerden y Watson 1988,111). Por la evidente diferencia en el estilo pictórico, formato en general y la solidez del vaso, quizá, pertenezcan a dos alfares diferentes que emplearon una fuente de arcilla común.

Cronológicamente parecen responder a un fenómeno o moda generalizada en el Mediterráneo oriental de platos de engobe blanco de época bizantina, que serían el precedente del vidriado blanco bizantino, que aparece a principios del siglo VII d.C. En cambio, M. Gawlikowski considera que estos platos de Gerasa con engobe blanco son ejemplos tempranos del "clásico plato de Gerasa" (Gawlikowski 1986,118), a pesar de hallarlos en niveles inmediatamente anteriores a la construcción de la casa omeya de Gerasa que este investigador excavó. Por otro lado, en Alejandría existe una cerámica con engobe blanco datable en el siglo VII d.C. por su presencia junto con monedas de la reforma de 'Abd al-Malik (Rodziewicz 1976,61). También esta cerámica con cubierta blanca se ha localizado en Saraçhane, en Estambul (Hayes 1968,206).

Desgraciadamente las piezas del Macellum de Gerasa carecen de contexto arqueológico o estratigráfico para poder fecharlas con seguridad. Sólo podemos datarlas por afinidades estilísticas.

Por lo que se refiere al repertorio iconográfico podemos dividirlo según los motivos representados (6), esto es, principales y secundarios.

Los motivos principales son variados. Hay representaciones simples como una especie de flecha (fig.13,71), que aparece combinada con un geométrico de trazos ondulados en la forma 30 del grupo X de platos de Gerasa. Conocemos otro pequeño cuenco de engobe blanco del Museo Arqueológico de Ammán (Watson 1989. Fig.10,5), con la representación de un "Cupido" con flechas. Nuestra pieza puede tener carácter de representación simbólica (representación de las flechas en lugar de la figura completa de Cupido); o decoraciones de carácter vegetal como una roseta central (fig.13,70) con un motivo secundario geométrico de zig-zag, dispuesto en el borde del cuenco (forma 28B de los platos de Gerasa).

Las cráteras suelen aparecer flanqueadas por aves y la pieza del Macellum (fig.12,69) tiene en su zona periférica una serie de líneas o trazos ondulados. Es claramente un motivo simbólico cristiano musivo (Watson 1989,249), que aparece en la forma 18 de nuestra clasificación de platos de Gerasa.

Las figuras de animales también están representadas en los platos de engobe blanco, no en todas las ocasiones el animal representado ha podido ser identificado con seguridad, ya que en muchos casos, por el estado fragmentario de las piezas, pudiera tratarse de partes de escenas y no de figuras aisladas. Una de las más vívidas representaciones la constituye un animal (posiblemente un asno) de grandes orejas, corriendo (fig.13,72), que quizá pudo formar parte de una escena más compleja. Este motivo aparece en la forma 2 de nuestra tipología de platos de Gerasa. En

(6) Un unicum lo constituye una pieza casi completa, sin ningún tipo de decoración, cubierta en su totalidad por un engobe blanco (fig. 16,92). 
otro fragmento aparece dibujado un perro con un gran collar (fig.13,73). Los felinos tampoco están ausentes, en un fragmento se observan las garras desdibujadas este animal (fig.13,74).

Las representaciones de aves son menos abundantes en la variedad de engobe blanco, tan sólo contamos con un ejemplo (fig.13,75); en este fragmento se observan dos aves de perfil, una de ellas parece un pavo real, como simbología claramente cristiana.

Dęl análisis de las figuras humanas pintadas sobre engobe blanco se desprende que fueron realizadas por distintos pintores de calidad artística desigual. Por un lado, tenemos representaciones muy esquemáticas de manos claramente humanas (fig.13,76), una serie de rostros masculinos imberbes, siempre representados de frente (fig.14,78 y 79) y un busto masculino, también sin barba (7) flanqueado por motivos vegetales esquemáticos, posiblemente palmas, en la forma 16B de los platos de Gerasa (fig.14,80), quizá pueda tratarse de la representación de un mártir (8). Y por otro, una serie de fragmentos que muestran una decoración más cuidada, entre estos últimos destaca un fragmento de escena (fig.13,77) en la cual se muestran unas piernas de perfil, calzadas con unas sandalias, junto a un mueble con peana y otra pieza con un rostro humano barbado de frente (fig.14,81).

A pesar de la cronología tardía de los platos de Gerasa, curiosamente entre sus decoraciones hallamos motivos de carácter claramente pagano, como sátiros o representaciones del antiguo dios Pan. En la variedad de platos de engobe blanco no encontramos ninguno completo, sólo partes inferiores de esta figura mitológica (fig.14,82).

También hemos determinado la existencia de escenas más o menos reconstruibles, en su mayoría de carácter cinegético, como la representada en un plato casi completo de la forma 16A (fig.15,84). En esta pieza la figura central es un hombre vestido a la manera oriental con un gorro y calzas de tipo frigio, rodeado por cuatro aves, una de ellas ensartada en una lanza o flecha que el personaje sostiene con una mano, a su lado aparece una especie de felino o de perro. Sin lugar a dudas se trata de una escena de cacería, escenas que son bastante comunes en los siglos VI y VII d.C. (Watson 1989,249) sobre todo en los mosaicos de la región.

Otra escena similar pero más fragmentada, y realizada con estilo que capta el movimiento, es la de un pie humano de perfil con una cabeza de perro (fig.14,83), bien puede pertenecer a una escena de cacería o a una escena en la cual el animal ataca al personaje. Esta pieza no lleva el engobe blanco típico, pero si de un tono claro, de ahí que la incluyamos dentro de esta categoría de platos de Gerasa. Por último, y dentro de las escenas tenemos la parte inferior de un personaje flanqueado por dos aves (fig. 15,86).

Muy interesantes, aunque parciales y difícilmente traducibles, son las series de epígrafes griegos que aparecen en estos platos de Gerasa, como un epígrafe griego (fig.16,88), "O $\Sigma \mathrm{N}$... IEPO $\Sigma \lambda$ MI..... $\theta .$. ", con una roseta, que quizá, esté haciendo referencia a la ciudad de Jerusalén (Hierosolyma) u otro (fig. 15,87) " $\pi \omega \lambda \varepsilon . . . "$ (pole), cuya traducción pueda estar relacionada con el verbo griego " $\pi \omega \lambda \dot{\varepsilon} \omega$ ", relacionado con la venta, o con mercado. Aunque en este caso sería: " $\pi \omega \lambda \eta \pi \eta \rho \mathrm{cov}$.

(7) La representación de figuras masculinas barbadas, dentro de la iconografía de los platos de Gerasa es bastante rara.

(8) La identificación de algunos bustos masculinos con representaciones de mártires entre palmas la debemos al Dr. Fuentes, a quien tenemos que agradecer también la sugerencia sobre la estrecha relación con el mundo de la muerte de algunos de los motivos cristianos de los platos de Gerasa. 
Para terminar con las representaciones pintadas en los platos de Gerasa con engobe blanco habría que mencionar el hallazgo de una serie de motivos de carácter secundario, los cuales por el estado de conservación de las piezas no pueden ser asociados con ningún motivo central o principal. Estos van desde trazos indeterminados, a trazos ondulados (fig.16,91), retículas pintadas en pequeños cuencos de la forma 28A (fig.16,89) a series de espirales (fig.16,90).

\section{b) Platos de Gerasa de engobe naranja con decoración pintada}

Son los más abundantes y característicos. Los motivos se sitúan normalmente en el fondo, en el interior. Conocemos pocos motivos decorativos pintados completos, por ello, al tratarse en su mayoría de fragmentos, la relación forma-motivo decorativo pintado es poco conocida.

Se emplearon dos colores: blanco (para rellenar las figuras) y rojo oscuro (para delinear o aplicar detalles). La pintura varía en su adherencia con la pasta; a veces la pintura roja se adhiere fuertemente mientras que la blanca es más fugaz. En otras ocasiones la pintura roja sobre la blanca es la que se pierde con mayor facilidad por su escasa cohesión con la pasta, un ejemplo de este caso lo constituye un motivo geométrico (fig.11,59).

\section{b.1.) Platos de Gerasa decorados con pintura roja delimitadora sobre el engobe naranja directa- mente}

Este tipo de esquema decorativo se corresponde con el formato 1 de P. Watson $(1989,231)$. Los motivos decorativos principales se pueden dividir en ideogramas y figuraciones.

Las cruces de tipo griego están bien representadas. Tenemos una cruz griega ancorada con dos aspas cruzadas y un epígrafe en griego (fig.2,1), éste está dispuesto a su alrededor: “..Г $\gamma \mathrm{T} \omega$ K..”. Nuestro motivo es más completo que los publicados por P. Watson $(1989,261$. Fig.7,9). Epigráficamente puede relacionarse con alusiones a Cristo como algunas que aparecen junto a cruces en los mosaicos y frescos de algunos monasterios helénicos más tardíos, como " $\Gamma \mathrm{C} \overline{\mathrm{X} C}$

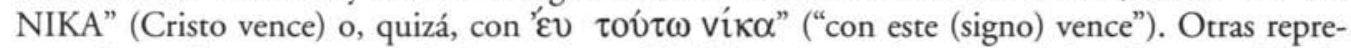
sentaciones de cruces son más incompletas (fig.2,2), en este ejemplo quizá se haya perdido la pintura blanca. El motivo es similar al publicado por P. Watson (1989. Fig.7,8).

Pero los motivos decorativos de carácter cristiano no se limitan a las cruces, sino también incluyen a otros objetos como las cráteras. Este último es un motivo muy abundante en las decoraciones musivas cristianas de la zona, puede aparecer aislado o con animales afrontados, tanto herbívoros como aves. Existen platos de Gerasa con esta decoración como el de la capa 3 de la cisterna del santuario de Zeus (Rasson y Seigne 1989. Fig.9) y los de Pella (Watson 1989. Fig.14, 4-6). Entre las piezas del Macellum de engobe naranja tenemos un ejemplo donde se muestra la parte inferior de una crátera (fig.2,3).

Las representaciones de aves, a diferencia de los platos de engobe blanco, son más abundantes y algunos ejemplos del Macellum proceden de depósitos bien fechados a mediados del siglo VI d.C. (fig.3,7), en una pieza casi completa se observa un ave de perfil, pintada en blanco delimitada por pinceladas en rojo, con pocos detalles anatómicos del plumaje y cabeza. En la forma 10 de platos de Gerasa parece ser un motivo central y no forma parte de escenas más complejas, por lo que puede tener una simbología cristiana, ya que es corriente en el siglo VI d.C. En la forma 17 de los platos de Gerasa, también hallamos aves pintadas (fig.3,11).

Otro ejemplo, mucho más realista, aunque realizado con la misma técnica, presenta a un ave de perfil con detalle del plumaje, pico y ojo (fig.2,6) presenta una cronología algo posterior, de finales del siglo VI d.C. o inicios del siglo VII d.C. En otras ocasiones la representación no es 
tan cuidada o fina, como el caso de un ave de perfil (fig.3,8), realizada a base de gruesas pinceladas de pintura roja.

El concretar el tipo de ave representado no suele ser fácil, excepto en el caso de animales exóticos como un avestruz (fig.3,9) con detalles del plumaje y unas largas patas. En otro caso, también pudimos determinar el tipo de ave representado como un pavo real (del cual sólo se conserva la cola) (fig.3,10).

Los peces, también de carácter cristiano, tienen sus ejemplos en el repertorio iconográfico de los platos de Gerasa, aunque sólo contamos con dos ejemplos: uno incompleto en el cual sólo se ve la cola (fig.4,12) referido al milagro de la multiplicación de los peces y los panes, al pescador de almas, etc. P. Watson publica motivos similares (Watson 1989. Fig.12) y otro más completo con detalle de las escamas (fig.4,13). Los peces pintados también son comunes en la cerámica copta (Emery y Kirwan 1938. Pl.114,89), contemporánea de los platos de Gerasa.

Un ejemplo único lo constituye la especie de serpiente pintada sobre la forma $28 \mathrm{C}$ de un plato de Gerasa (fig.4,16). Hasta la fecha no conocemos ningún ejemplo similar a este motivo.

Hay numerosas representaciones musivas de animales cuadrúpedos, en su mayoría de origen exótico, en iglesias bizantinas, como en Monte Nebo (Piccirillo 1988,40). Las representaciones de felinos son bastante corrientes en los platos de Gerasa, algunas son incompletas, como las garras de un felino agazapado (fig.4,14), otras son más realistas, como la representación de un felino de perfil, con un único ojo pintado de frente y las fauces abiertas (fig.4,15), puede tratarse de una leona o de una pantera. Existe un paralelo a este motivo, procedente de Gerasa, de la cisterna del templo de Zeus de Gerasa, concretamente de la capa 3, datada como bizantina (Rasson y Seigne 1989. Fig.8).

En cuanto a las representaciones humanas, aunque son más abundantes son bastante parciales. Por ello hay que señalar que muchos motivos decorativos pudieran formar parte de escenas más complicadas, cuyo significado, por nuestro conocimiento parcial de las mismas, se nos escapa y que, quizá, debieran estar incluidas dentro del motivo decorativo de escenas.

Los motivos más fragmentarios los constituyen unas series de manos, una sosteniendo una especie de haz (fig.4,17). La representación personificada de las estaciones es muy corriente en la zona, desde épocas más antiguas (Watson 1989,245). En otro fragmento una mano sosteniendo una flor (fig.4,18), y en otro una mano sosteniendo o recogiendo uvas (fig.6,26), que pudo constituir una escena de recolección o vendimia, muy habitual en los mosaicos de Madaba del siglo VI d.C. (Piccirillo 1988,76) y en los de Scythopolis (Fitzgerald 1939,9).

También partes inferiores de personajes, como unos pies descalzos en la forma 16A de platos de Gerasa (fig.5,24), otra con más detalle de la vestimenta de tipo frigio, con una especie de calzas (fig.6,25). Vestimentas de este tipo también fueron advertidas por P. Watson $(1989,249)$ y una representación de un pie de perfil con una sandalia (fig.6,28) en la forma $29 \mathrm{~F}$ de platos de Gerasa. Los rostros masculinos también están presentes (fig.6,27, 29-31).

Otras figuraciones son algo más completas como un torso de perfil con el brazo flexionado (fig.5,19 y 20). Un pequeño fragmento muestra con más detalle la túnica y quizás un medallón colgado al cuello del personaje (fig. 5,21 ) y una figura femenina vestida con una túnica con los brazos flexionados extendidos hacia delante en actitud de saludo o quizás oferente (fig.5,22).

Las representaciones masculinas son más abundantes que las femeninas, en una base se observa un personaje con los cabellos hasta la altura del cuello, con el torso de frente sosteniendo dos varas (fig.5,23).

Las figuraciones mitológicas no están ausentes, la más popular fue la del sátiro o dios Pan (que aparece en la forma 29D), con el rostro y el torso de frente, y las extremidades de perfil. 
Con la mano sostiene una especie de flauta o lira. A su alrededor se dispone un motivo vegetal secundario (fig.7,32). Es muy similar al publicado por P. Watson (1989. Fig.10,1), que parece inspirarse en fuentes clásicas, se conocen cuatro ejemplares, a parte de los del Macellum de Gerasa, con esta decoración (Watson 1989,245). Dos fragmentos más problemáticos están constituidos por la parte inferior de unas pezuñas; el primero pudiera corresponder a las patas traseras de un herbívoro (fig.7,33) y el segundo a los cuartos delanteros de un caballo (fig.7,34).

Las escenas tampoco son muy completas, este tipo de representaciones dentro de la iconografía bizantina no son raras, sobre todo las cinegéticas o la de vendimia, que aparecen corrientemente en los mosaicos de las iglesias tardobizantinas. Su significado está por determinar. Muchas son escenas de caza: en un fragmento se observa un personaje vestido con una especie de "faldilla" corta y un cuadrúpedo a su lado (fig.7,35).

Todos los epígrafes griegos son incompletos. En algunas ocasiones aparecen siglas alrededor de otros motivos simbólicos centrales, como las cruces (tendrían carácter cristiano). Quizá muchos otros estén relacionados con el fabricante (Watson 1989,261) o el poseedor del plato en cuestión y a veces hacen referencia a la figura que aparece sobre el plato. Todos aparecen en fragmentos de bases, como " $\kappa<\Delta \omega N$....." (fig.2,4) o "... $\lambda \pi .$. ." junto con el pico de un ave de perfil (fig.2,5). Desgraciadamente ninguno ha podido ser traducido.

Los motivos secundarios pueden dividirse en geométricos y vegetales. Aparecen, en su mayoría, en fragmentos de bordes, y por lo tanto, en formas incompletas.

Los geométricos son los más abundantes, pero posiblemente formaran parte de decoraciones más complejas, suelen situarse en las zonas periféricas de los platos, como una banda blanca delimitada por líneas horizontales en rojo (fig.7,36), trazos indeterminados, trazos ondulados, línea ondulada (fig.7,37), línea horizontal con pequeños círculos unidos a ella (fig.8,38), banda blanca delimitada por dos líneas en rojo horizontales y pequeños círculos rojos en su interior (fig.8,39) que es similar a la hallada en una jarra copta (Egloff 1977. Pl.96,66). También motivos seriados: banda de triángulos en rojo (fig.8,40) o una línea horizontal con series de semicírculos con puntos en su interior (fig.8,41).

Los vegetales, aunque menos numerosos, también están presentes, van desde los más simples (quizá también formaron parte de escenas completas en el pasado), como una gran hoja radiada (fig.8,43), otra menos detallada (fig.8,42), especie de roleos vegetales, que aparece en la forma 15 de esta producción (fig.8,44), forma que se inspira en la terra sigillata chipriota tardia, hasta una especie de espiga (fig. 9,45 ) que puede estar relacionada con una escena de siega, motivo que es ya conocido en otros platos de Gerasa (Watson 1989. Fig.9,7).

Por último, y dentro de este apartado tenemos un plato casi completo de la forma 26 (fig.9,46) en el cual se combinan series de círculos concéntricos con un motivo que podemos denominar estilización de orlas de pámpanos. P. Watson publica este mismo motivo, que acompañan a motivos simbólicos, como panes y peces (Watson 1989. Fig.8,3), cesto de panes (Watson 1989. Fig.8,4), Cristo Pantócrator (Watson 1989. Fig.9,1), aves (Watson 1989. Fig.11,3 y 5), animales (Watson 1989. Fig.12,11) y cráteras (Watson 1989. Fig.14,4-6).

\section{b.2.) Platos de Gerasa pintados en rojo sobre círculo central en blanco.}

Esta serie decorativa pertenece al esquema 2 de P. Watson $(1989,231)$, y técnicamente este tipo de decoración es muy similar, casi igual, al anterior b.1. Pero por corresponder a una distribución del espacio decorativo muy concreta, su estudio y clasificación se realizó por separado. 
Las series exclusivamente geométricas están compuestas, en su mayoría, por círculos centrales y concéntricos. Los más simples son: un círculo central pintado en blanco, que aparece en la forma 10 (fig.9,48); un círculo en blanco delimitado por dos círculos concéntricos pintados en rojo (fig.10,49); un círculo central rodeado por otro concéntrico (fig.10,50); un círculo central en blanco con dos círculos concéntricos en rojo en su interior (fig.10,51); dos círculos concéntricos en blanco (fig.10,52) o en rojo (fig.10,53); o un círculo central con un círculo concéntrico exterior sobre el que se disponen una serie de semicírculos en rojo, en la forma $1 \mathrm{C}$ de nuestra clasificación de platos de Gerasa (fig.11,60).

Hay otros ejemplos más complejos, ya que aparte de tener el círculo central en blanco presentan series geométricas, como series de semicírculos pintados en rojo (fig.10,54), series de triángulos también en rojo (fig.10,55) o un círculo en blanco rodeado en el exterior por una doble línea en zig-zag y puntos.

Otra serie la constituyen unos octógonos radiados incluidos en el círculo central, algunos simples (fig.10,56), otros dobles (fig.10,57) y otro con los radios acabados en un engrosamiento (fig.11,58) en la forma 3. P. Watson (1989. Fig.7,2) publica un motivo similar que denomina "guirnalda punteada" ("dotted Garland"). Al contrario de otros motivos de los platos de Gerasa, no hay ni un sólo motivo musivo en el que se pudieran inspirar los alfareros o pintores de los platos de Gerasa para realizar este motivo decorativo. Este motivo es bastante conocido en Gerasa, en los platos de producción local. P. Watson lo incluye dentro de su esquema II de abanico/roseta (Watson 1989,257). Otro ejemplo, no muy bien conservado es el de un círculo central en blanco con series de octógonos radiados y un círculo concéntrico rodeándole (fig.11,59), este octógono, quizá, en origen estuviera pintado en rojo, pero por la aplicación lenta de esta pintura se haya diluido en la pintura blanca. En un fragmento de base se ven dos círculos blancos, en el exterior una serie de trazos semicirculares, y en el interior un octógono radiado en pintura roja (fig. 11,61 ).

Sobre estos círculos centrales no sólo aparecen motivos geométricos, sino también vegetales estilizados (fig.11,64).

Entre los motivos cristianos tenemos cruces griegas, en un ejemplo aparece una cruz griega ancorada con dos aspas cruzadas y un círculo alrededor del central con una línea ondulada en rojo, aparece en la forma 10 (fig.12,66). Es similar al motivo de P. Watson (1989. Fig.7,9), y es un motivo popular en los siglos VI y VII d.C. (Watson 1989,242). En otro caso, sobre el círculo central blanco se dispone una cruz, con uno de los brazos terminados en estilizaciones de pámpanos (fig.11,63) con, quizás, un epígrafe en griego: "HI...KC".

Otra representación cristiana la constituye un círculo central con una cesta, quizás, de panes en rojo en su interior (fig.12,67). Posiblemente está relacionado con el milagro de la multiplicación de los peces y los panes. P. Watson publica un símbolo similar (Watson 1989. Fig.8,1), que puede ir aislado o ir rodeado de peces.

Los epigráficos están escritos en griego. Con este tipo de esquema compositivo tan sólo hemos hallado uno (fig.12,68) con series de círculos concéntricos blancos con un epígrafe incompleto en el exterior: "... $\chi \chi \ldots .$.

\section{2.- Decoración estampillada}

Este tipo de decoración sobre los platos de Gerasa hizo que muchos de ellos fueran, en un principio, clasificados como terra sigillata tardía o pseudo-sigillata. Esta técnica decorativa, sin 
duda, afirma la hipótesis de la directa derivación o inspiración de estos platos locales en la terra sigillata africana. No pueden considerarse como un grupo aparte de los platos de Gerasa pintados, no sólo por que las pastas son exactamente iguales, como lo demuestran los análisis de pastas (Duerden y Watson 1988), sino por que existen formas que comparten ambos tipos de decoración.

Dentro de los tipos estampillados hay que diferenciar dos clases, los estampillados simples, de los cuales sólo tenemos un ejemplo (fig.16,93), y los estampillados inscritos en círculos incisos concéntricos (estos últimos más abundantes).

\section{a) Platos de Gerasa con decoración estampillada simple}

Con este tipo de decoración tan sólo conocemos un ejemplo del Macellum de Gerasa, que carece de contexto arqueológico y, por lo tanto, aporta poca información, pero el tipo de decoración, rostro humano de frente y palmeta dispuestos alternativamente en círculo (fig.16,93) recuerda mucho a las estampillas africanas.

\section{b) Platos de Gerasa con círculos concéntricos incisos y estampilla central}

Una de las características principales de estas producciones es su decoración pintada, de ahí que tan sólo se clasificaran como platos de Gerasa aquellas formas decoradas con pintura blanca y roja. Ańos más tarde se asociaron a esta manufactura local toda una serie de producciones con decoración estampillada. P. Watson fue una de los primeros investigadores en darse cuenta de ello: "A subdivision of this group consist of some of the same forms and ware but has an interior decorated with incised concentric circles around a small central stamp" (Ball, Bowsher, Kehrberg, Walmsley y Watson 1986,365).

El esquema decorativo es muy similar al de la terra sigillata africana. Son series de círculos concéntricos con estampilla en el centro, como medallones. La impresión de los punzones es menos profunda que la del grupo decorativo anterior de estampilla aislada.

Fundamentalmente las estampillas son de tipo vegetal, como una palmeta simple (fig.16,94) o una palmeta rodeada de "perlitas" (fig.17,95), rosetas (fig.17,96) y algunas indeterminadas (fig.17,97).

\section{3.- Decoración incisa}

Los platos de Gerasa con decoración incisa son menos abundantes que el resto. Por el estado fragmentario de las piezas recogidas con este tipo de decoración, no se pueden adscribir, por el momento, a ninguna forma cerámica en concreto, excepto la forma $28 \mathrm{D}$, que es la única con perfil completo.

Resulta curioso que también en Cartago, en la zona excavada por el equipo británico, se haya descubierto terra sigillata africana con decoración incisa de un "pez", lo cual no es nada corriente dentro de la tradición decorativa norteafricana (Fulford y Peacock 1984,97. Fig.30,116).

Los motivos son tanto cristianos: cruz griega rodeada de espirales (fig.17,98) o una crátera central rodeada por círculos concéntricos incisos (fig.17,100), como figuras humanas: en la forma 28D de platos de Gerasa (fig. 18,101), en cuyo interior aparece un rostro masculino de frente imberbe con un epígrafe inciso incompleto, y por lo tanto, intraducible: “..NIOYO.." y escenas (fig. 17,99): donde se representa el cuello y parte inferior de la cabeza de un caballo atacado por un felino. 


\section{4.- Decoración incisa e impresa}

La disposición de estos, sin duda, repite el mismo esquema decorativo de los platos de Gerasa con motivos en rojo sobre círculo blanco central.

El tipo de ruedecilla empleada en los platos de Gerasa no es privativo de este tipo cerámico, sino que lo encontramos también en la cerámica común, lo que sí resulta característico, es la disposición en círculo que adopta esta impresión en los platos de Gerasa. Los círculos concéntricos incisos se realizaban antes, con compás, y servían de patrón-guía para el posterior desarrollo de la decoración impresa a ruedecilla (fig.18,102).

Otro ejemplo, muy distinto lo constituye los cuartos traseros de caballo incisos rodeados de un círculo realizado en ruedecilla.

\section{5.- Decoración pintada, impresa e incisa}

Por disponerse la decoración pintada sobre el círculo central blanco y la incisa e impresa a su alrededor podemos decir que sigue el mismo esquema decorativo de los platos pintados con círculo central blanco.

Algunos ejemplos muestran una decoración pintada indeterminada (fig.18,104). Aunque existe otro ejemplo más complicado, con dos círculos concéntricos incisos, sobre los cuales se desarrolla una decoración impresa a ruedecilla, todo ello rodeando un círculo pintado en blanco, sobre el que se sitúa una escena pintada en rojo, un torso humano con una cruz al cuello, piernas de perfil y un epígrafe en griego incompleto: " $\varepsilon \lambda \lambda \ldots . . . "$.

\section{6.- Decoración incisa y pintada}

Sólo existe un ejemplo de este tipo de decoración en el Macellum de Gerasa, y es un círculo pintado en blanco y círculos concéntricos incisos, en una base anular de un plato de Gerasa.

\section{3.- ESTILOS DECORATIVOS}

Aunque aún no estamos en condiciones de adjudicar distintas cronologías a los diferentes estilos pictóricos detectados y mucho menos adjudicar estos estilos a los pintores que trabajaban en cada alfar (9) de Gerasa, hemos podido definir estos estilos a grandes rasgos.

Estilo I: muestra una técnica muy concisa, en la cual se emplea la pintura roja para delimitar y delinear detalles en las figuras, sobre la pintura blanca (fig.2,1 y 6. Fig.3,10). En las representaciones humanas se sigue un estereotipo: la cabeza y el torso de frente y las extremidades de perfil. Una excepción a esta regla la constituye la figura femenina con túnica (fig.5,22) cuyo torso está pintado de perfil. En cambio las figuras de animales se representan siempre totalmente de perfil, con un único ojo (fig.4,15). Este estilo aparece en los platos de Gerasa pintados sobre engobe naranja, en general, en algunos ejemplos con engobe blanco (fig.13,77 y fig.14,81) y en algunas decoraciones mixtas (fig.18,105). Los tipos representados son tanto figurados como geométricos.

(9) Aunque en las excavaciones del Macellum hemos detectado algún fragmento con defecto de cocción, los hornos que produjeron los platos de Gerasa permanecen desconocidos hasta la fecha. 
Estilo II: siempre realizado con pintura sobre engobe blanco o crema, con una línea muy fina se dibujan los motivos decorativos que, hasta la fecha, son todos de carácter figurado (fig. 13,73 y 75 y fig. 14,83).

Estilo III: se caracteriza por líneas gruesas en color rojo que delimitan a las figuras pintadas en blanco, resultando unas representaciones muy concisas, aunque desde luego no tan finas como las del anterior estilo (fig.3,8, fig.5,19 y fig.7,34). También son todos motivos figurados.

Estilo IV: estilo ingenuo o "naif" que es privativo de los platos de Gerasa con engobe blanco. Las representaciones humanas siguen el mismo estereotipo del estilo I, pero aún más marcado. Apenas se dan detalles anatómicos (fig. 14,79 y 80 y fig.15,84 y 86). En las representaciones figuradas y simbólicas pintadas en este estilo son las mismas que las del estilo I.

\section{4.- CORRIENTES ICONOGRAFICAS}

Por lo que se refiere a los motivos decorativos figurados vemos como se pueden clasificar grosso modo, dentro de dos corrientes iconográficas: una religiosa cristiana y otra "laica" o incluso claramente pagana.

El repertorio iconográfico es muy rico y recoge tradiciones muy distintas, encontrándose imagenes paganas como la del dios Pan o un sátiro, símbolos cristianos, como cruces griegas, y escenas sin aparente significado ideológico, como escenas cinegéticas. Para P. Watson esta diversidad responde simplemente a las demandas de un mercado compuesto por gentes de muy distintas ideologías, que conviven dentro de los mismos núcleos urbanos (Watson 1989,252). Este hecho no resulta extraño, ya que se conocen ejemplos de esta convivencia en decoraciones de terra sigillata africana de la forma Hayes 56, con motivo pagano (Garbasch 1980,87) y otro recipiente de la misma forma con motivo cristiano de san Pedro y san Pablo (Bejaoui 1984,45).

Por otro lado, a pesar de las opiniones de Iliffe o de Gawlikowski sobre la cronología de estos platos, somos de la misma opinión de P. Watson, autora que reconoce que dentro de la iconografía de los platos de Gerasa no hay ningún elemento islámico: "As the dating of the Jerash bowls group would suggest however, nothing identificably islamic is evident in their decoration or inscriptions" (Watson 1989,242).

\section{1.- Corriente cristiana}

La primera corriente, la religiosa, se inspira fundamentalmente en los mosaicos que decoran las iglesias bizantinas de Oriente del siglo VI d.C., como las cráteras flanqueadas por aves, escenas de vendimia (Fitzgerald 1939), representaciones personificadas de las estaciones de la iglesia de al-Hammäm, cerca de Scythopolis (Fitzgerald 1939,7), etc.

Las cráteras que, quizá, estén en relación con la Eucaristía, en Jordania también aparecen en los mosaicos de las iglesias bizantinas, como en el situado bajo la capilla del Padre Juan de Wäd $\vec{\imath}$ Afrit y que se fecha a finales del siglo V d.C. (Piccirillo 1988,88-89), aunque en Monte Nebo, en el ábside del santuario primitivo, está representada una crátera que se fecha en el siglo IV d.C. (Piccirillo 1988,34-35). Por lo que este motivo existía ya antes de la aparición de los platos de Gerasa.

Las cestas de panes, al igual que otros motivos representados en los platos de Gerasa, parecen inspirarse en los mosaicos de las iglesias, de ahí que los hayamos considerado como un motivo cristiano. Aparecen en la capilla del Padre Juan en Wädì Afrit, cuyo mosaico se fecha a mediados 
del siglo VI d.C. (Piccirillo 1988,87), y en la iglesia bizantina de al-Hammäm en Scythopolis (Avi-Yonah 1935. PI.XVI,2). Según P. Watson $(1989,245)$, parece que representarían el milagro de la multiplicación de los peces y los panes atribuido al yacimiento de Tabgha donde hay un mosaico con un motivo similar.

La representación de peces, está relacionada con el motivo anterior, técnicamente su representación en los mosaicos se remontaría a época romana, con los motivos musivos de carácter nilótico, como los hallados en la iglesia de Kissufim del siglo VI d.C. (Metropolitan 1986,242). En los platos de Gerasa debemos relacionar este motivo con el milagro de la multiplicación anteriormente mencionado. Según G. Cornfeld (Cornfeld y Freedman 1976,327), los peces asociados a anclas en Palestina, en monumentos funerarios, así como en las catacumbas de Priscila de Roma, se veían como signos de esperanza.

Las aves se consideran, en general, como animales del paraíso, es quizás el animal más representado en el arte musivo. Las aves exóticas como el avestruz también tienen paralelos en los mosaicos del Diaconicon-Baptisterio de Monte Nebo (Piccirillo 1988,40) fechado en el primer tercio del siglo VI d.C., en el mosaico de la iglesia de san Juan Bautista de Gerasa del 531 d.C. (Browning 1982,99. Fig.39) y en la iglesia de Tabgha, en el mar de Galilea, fechada en el siglo VI d.C. (Metropolitan 1986. Fig.80).

El pavo real (símbolo de la incorruptibilidad de la carne) también está representado en mosaicos fechados a mediados del siglo VI d.C., como en la capilla del Padre Juan, adosada a la iglesia de Amós y Casieo en Wädì Afrit ((Piccirillo 1988,83) y en los de al-Ḥammäm cerca de Scythopolis (Avi-Yonah 1935. PI.XIV).

Algunos motivos secundarios de carácter vegetal, también se inspiran en las decoraciones de los mosaicos, como las orlas de pámpanos, que son un motivo musivo desarrollado desde el siglo II al III d.C. en el norte de Africa, peró en los mosaicos jordano-palestinos debe fecharse desde mediados del siglo VI d.C. (Avi-Yonah 1935,19-20) y resulta una decoración predominante en los mosaicos de Scythopolis (Fitzgerald 1939,9), también en los mosaicos de Monte Nebo, en la iglesia de los santos Lot y Procopio (Piccirillo 1988,80), que se fecha a mediados del siglo VI d.C. (Piccirillo 1988,74). Estas orlas de pámpanos estilizadas quizás aludían al misterio de la Eucaristía, de ahí que sean tan abundantes las representaciones de la vendimia en las iglesias de la zona, como la de san Jorge del 536 d.C. (Piccirillo 1988,66).

Los octógonos radiados, según P. Watson $(1989,252)$, puede ser un símbolo de regeneración $\mathrm{y}$ renacimiento por medio del Bautismo.

Las serpientes, aunque no muy abundantes, pueden constituir un signo profético derivado del Antiguo Testamento, transmutado en términos escatológicos: la serpiente de Moisés (Cornfeld y Freedman 1976,30) algo así ocurriría con el árbol de la vida, a veces representado en los platos de Gerasa.

Las escenas cinegéticas (tanto en las que intervienen seres humanos cazando animales, como en la que representan animales carnívoros atacando a animales herbívoros), aunque su significado cristiano se nos escapa, también se inspiran en el arte musivo de la zona, como en los mosaicos de Monte Nebo (Piccirillo 1988,37).

Las cruces son sin duda el motivo más innegablemente cristiano, del cual no hay paralelos exactos en los mosaicos de las iglesias. El tipo representado es el griego, y numerosas veces aparece con dos aspas cruzadas (Crismón). Según Cornfeld, la cruz con el signo $\chi$ enfatiza la redención de Cristo y la realización del drama escatológico (Cornfeld y Freedman 1976,308). 
Algunos de los motivos epigráficos, relacionados con ciudades santas, como Jerusalén, también aparecen en los mosaicos de Madaba. Menciones a ciudades están documentadas en Gerasa, como en el mosaico de la iglesia de san Juan Bautista con representaciones de ciudades o santuarios con un significado claro para los cristianos (Browning 1982,99).

Otras decoraciones de las cuales no tenemos paralelos conocidos pudieron inspirarse en frescos o en iconos que parece que se pueden remontar al siglo VI o VII d.C. (Mango 1987,36), que por su carácter perecedero no han llegado a nuestras manos.

\section{2.- Corriente pagana o no cristiana}

En cuanto a las figuraciones de tipo pagano, como sátiros o cupidos, parece un fenómeno de la antigüedad tardía la convivencia de ambas corrientes decorativas en el Mediterráneo, lo que no sabemos es si la existencia de estos motivos "paganos" implica la supervivencia del culto a los antiguos dioses en Gerasa o simplemente responde a un gusto decorativo antiguo. Seguramente, estas imagenes, perdieron su antiguo significado, o también pudieron estar dirigidas a un sector de la población no cristianizado.

Otras representaciones, de aspecto "laico", como algunos animales salvajes como felinos, según P. Watson, tienen sus orígenes en el arte persa y mesopotámico. Estos motivos fueron incorporados al arte iconográfico occidental de forma continua y durante muchos siglos (Watson 1989,249). Pero pensamos que este tipo de motivos más bien pudieron inspirarse en los ejemplos más cercanos de los mosaicos del siglo VI d.C.

Los más claros ejemplos de esta corriente "laica" los constituyen algunos epígrafes (fig.15,87) relacionados con actividades comerciales.

Merece la pena, también, antes de terminar este apartado, mencionar el tipo de vestiduras que llevan los personajes representados en los platos de Gerasa. Estas son en su mayoría de estilo oriental. Los gorros apuntados y los pantalones de tipo frigio son una constante. P. Watson $(1989,249)$ apuntó a que quizás la breve dominación persa sasánida de Gerasa, del 614 al 628 d.C. esté reflejada en este tipo de vestimenta. Esta hipótesis no parece cierta, ya que en este yacimiento no se ha observado ningún cambio tangible en el resto de las producciones cerámicas, ni ningún episodio de destrucción violenta relacionado con esta conquista. Además, personajes ataviados de esta guisa aparecen ya en un mosaico de Nebo fechado en el 531 d.C. (Piccirillo 1988,37), esto es, muchos años antes de esta conquista.

\section{5.- CONCLUSIONES}

La iconografía de los platos de Gerasa, analizada desde un punto de vista exclusivamente religioso, nos lleva a los origenes de las representaciones cristianas más arcaizantes. Las imagenes que estos platos muestran, aves del paraíso, el pavo real como símbolo de la incorruptibilidad de la carne, la cruz como símbolo del drama escatológico, imagenes de mártires, decapitación de san Juan Bautista (Watson 1989. Fig.10,9), vides estilizadas relacionadas con la Eucaristía, el octógono como nacimiento después de la muerte o tras el Bautismo, etc. nos acercan al cristianismo primigenio, en el cual todo lo relacionado con la muerte fue de vital importancia. Por ello, el desarrollo de las decoraciones de tipo cristiano y la creación misma de los platos de Gerasa en esta zona del Imperio, testigo del nacimiento de la nueva religión, no nos deben resultar extraños. 
Pero, por otro lado, el encontrar decoraciones como cruces con epígrafes alusivos a Cristo no quiere decir que los platos de Gerasa estén unidos directa y exclusivamente a lo eclesiástico, sino que pueden relacionarse con utensilios de la vida cotidiana. Parece que en los siglos VI y VII d.C. era algo normal encontrar representaciones religiosas en objetos de uso cotidiano. Esta idea también está apoyada por el profesor C. Mango (1987,35): “We try, therefore, to cast our minds back to 730 (and earlier) and what do we find? Religious images are everywhere, in churches, in private houses, on public monuments, in books, on utensils".

En conclusión podemos decir que las representaciones iconográficas de los platos de Gerasa y su misma producción están aludiendo, sin duda, a la realidad socio-económica y cultural de la provincia de Arabia en el siglo VI d.C. En concreto a una gran ciudad, relacionada con las rutas caravaneras, Gerasa, que fue capaz de crear sus propias producciones cerámicas de lujo y de importarlas a otras ciudades situadas a lo largo de la Via Nova Traiana. Y los motivos decorativos, tan variados, responderían a una población cosmopolita y heterogénea.

Además, el final de esta producción, acelerado, sin duda, por la conquista islámica de la región, que se sitúa hacia inicios del segundo tercio del siglo VII d.C., hace que los platos de Gerasa sean uno de los "fósiles-guía" más valiosos de la arqueología tardobizantina jordana. 


\section{BIBLIOGRAFIA.}

Avı-YonaH, M, 1935: “Mosaic pavements at El Ḥammām, Beisan”. Q.D.A.P, V, (1-2). Londres, 11-30. Ball, W. Bowsher, J. Kehrberg, I. Walmsley, A. y Watson, P, 1986: "The North Decumanus and North Tetrapylon at Jerash: an Archaeological and Architectural Report". Jerash Archaeological Project 1981-1983, I. D.A.J. Ammán, 251-409.

BejaOUI, F, 1984: "Pierre et Paul sur noveaux fragments de céramique africaine". R.A.C. Roma, 45-62.

BRAEMER, F, 1989: "Une fabrique (locale?) de céramique fine à Jerash au tournant de l'ère". En Jerash Archaeological Project 1984-1988, II. Syria, LXVI. París, 153-167.

BROWNING, I, 1982: "Jerash and the Decapolis". Londres.

Cornfeld, G. y Freedman, D. N., 1976: "Archaeology of the Bible: Book by book". Harper and Row publishers. San Francisco.

DUERDEN, P. y WATSON, P, 1988: "PIXE-PIGME Analysis of a series of Byzantine Painted Bowls from Northern Jordan”. Mediterranean Archaeology, I. Sidney, 97-111.

Egloff, M, 1977: "Kellia". Recherches suisses d'Archéologie Copte III, vol. 1 y 2. "La poterie copte". Ginebra.

EMERY, W. B. y KIRWAN, L. P., 1938: "The Royal Tombs of Ballana and Qustul". Service des Antiquités de L'Egypte. El Cairo.

FiSHER, C. S. y Mc Cown, C. C., 1931: “Jerash-Gerasa 1930". A.A.S.O.R, 11. New Haven, 1-59.

Fitzgerald, G. M., 1939: “A Sixth century Monastery at Beth-Shan (Scythopolis)". Publications of the Palestine Section of the University Museum. University of Pennsylvania. Filadelfia.

FRANKEN, H. J. y KALSBEEK, J., 1975: "Potters of a medieval village in the Jordan valley". North-Holland ceramics studies in Archaeology, No 3. Amsterdam-Oxford.

Fulford, M. C. y PeACOCK, D. P. S., 1984: “Excavations at Carthage. The British Mission, 1,2. The Avenue of President Habib Bourguiba, Salammbo. The Pottery and others Ceramic objects from the site". Sheffield.

GARBASCH, J., 1980: “La vie d'Achille et autres plats rectangulaires en sigillée claires 'D'”. Actes du Colloque sur la céramique antique. Cartago, 87.

GaWLIKOWSKI, M., 1986: "A Residential area by the South Decumanus". Jerash Archaeological Project 1981-1983, I. D.A.J. Ammán, 107-136.

GAWLIKOWSKI, M. y MUSA, A., 1986: "The church of Bishop Marianos". Jerash Archaeological Project 1981-1983, I. D.A.J. Ammán, 137-162.

HAYES, J. W., 1968: “A Seventh Century Pottery group”. Dumbarton Oaks Papers, 12. Washington, 203216.

... 1972: "Late Roman Pottery. A catalogue of roman fine wares". The British School at Rome. Londres.

Homes-Frederice, D. y Franken, H. J., (ed.) 1985: "Argile, source de vie. Sept millenaires de céramique en Jordanie". Documents du Proche-Orient ancien. Expositions Temporaires, N. 3. Musées Royaux d'Art et d'Histoire. Bruselas.

ILIFFE, J. H., 1945: "Imperial Art in Transjordan. Figurines and Lamps from a Potter's store at Jerash". Q.D.A.P., XI. Londres, 1-26.

MANGO, C., 1987: "The cult of icons". "From Byzantium to El Greco (greek frescoes and icons)". Catálogo de la exposición. Grecia, 35-36.

Metropolttan, 1986: "Treasures of the Holy Land (Ancient Art from the Israel Museum)". The Metropolitan Museum of Art. Nueva York.

MiChalOWSKı, K., 1962: "Palmyre. Fouilles Polonaises 1960". La Haya-París. 
Montlivault, E. de, 1986: "Remarques sur un lot de céramique d'époque byzantine". Jerash Archaeological Project 1981-1983, I. D.A.J. Ammán, 71-73.

PARKer, T. S., 1987: "The Pottery". Capítulo 18 de "The Roman Frontier in Central Jordan. Interim Report on the Limes Arabicus Project 1980-1985". B.A.R. Inter. Series, 340. Oxford, 525-619.

Piccirillo, M., 1988: “La Montagna del Nebo". Studium Biblicum Franciscanum, guide, 2. Franciscan Printing Press. Ammán.

Pierobon, R., 1986: "The Area of the Kilns" en "The italian activity within the Jerash Project 19821983”. Jerash Archaeological Project 1981-1983, I. D.A.J. Ammán, 184-188.

Rasson, A-M, 1987: “Les bols de Jerash”. Archaeologia. Dossiers d'Archéologie. Dijon, 63.

RASSON, A-M. y SEIGNE, J., 1989: "Une citerne byzantino-omeyyade sur le Sanctuarie de Zeus". Jerash Archaeological Project 1984-1988, II. Syria, LXVI. París, 117-151.

Rodziewicz, M., 1976: “La céramique Romaine Tardive d'Alexandrie”. En Alexandrie I. Centre d'Archéologie Méditerranéenne de l'Academie Polonaise des Ciences. Varsovia.

SAller, S., 1957: "Excavations at Bethany (1949-1953)". Publications of the Studium Biblicum Franciscanum, 12. Jerusalén.

SAUER, J. A., 1973: "Heshbon pottery 1971. A Preliminary Report on the Pottery from 1971. Excavations at Tell Hesbân”. Andrews University Monographs Studies in Religion, 7. Berrien Springs, Michigan.

SCHeneider, H., 1950: "The Memorial of Moses on Mount Nebo. Part III. The Pottery". Publications of the Studium Biblicum Franciscanum, 1. Jerusalén.

Tushingham, A.D., 1972: "The Excavations at Diban (Dhibân) in Moab. Third campaign 1952-53". A.A.S.O.R., XL. Cambridge.

USCATESCU, A., 1993: “La cerámica tardorromana y bizantina del Macellum de Gerasa (Jerash, Jordania)". (Tesis doctoral en microfichas). Ediciones de la Universidad Autónoma de Madrid. Madrid.

WALMSLEY, A., 1988: "Pella/Fihl after the Islamic conquest (A.D. 635- c.900): A Convergence of Literary and Archaeological evidence". Mediterranean Archaeology, I. Sidney, 142-159.

WATSON, P., 1989: "Jerash bowls: study of a provincial group of Byzantine decorated fine ware". Jerash Archaeological Project 1984-1988, II. Syria, LXVI. París, 223-261.

WINNETT, F. V. y REED, W. L., 1964: “The excavations at Dibon (Dhibân) in Moab, 1957-1958". A.A.S.O.R., XXXVI-XXXVII (1957-1958). New Haven. 


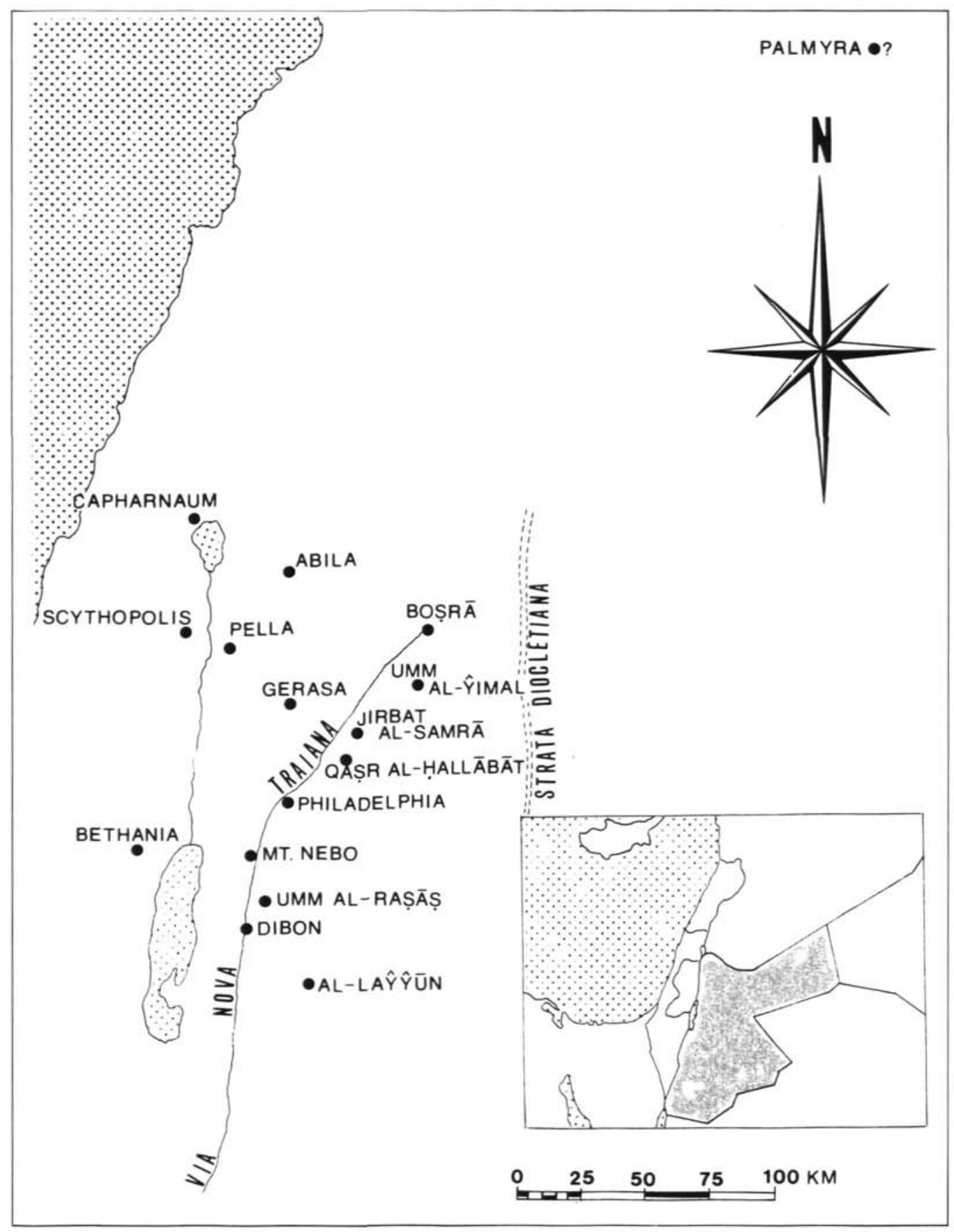

Figura 1. Mapa de distribución de los hallazgos de platos de Gerasa. 


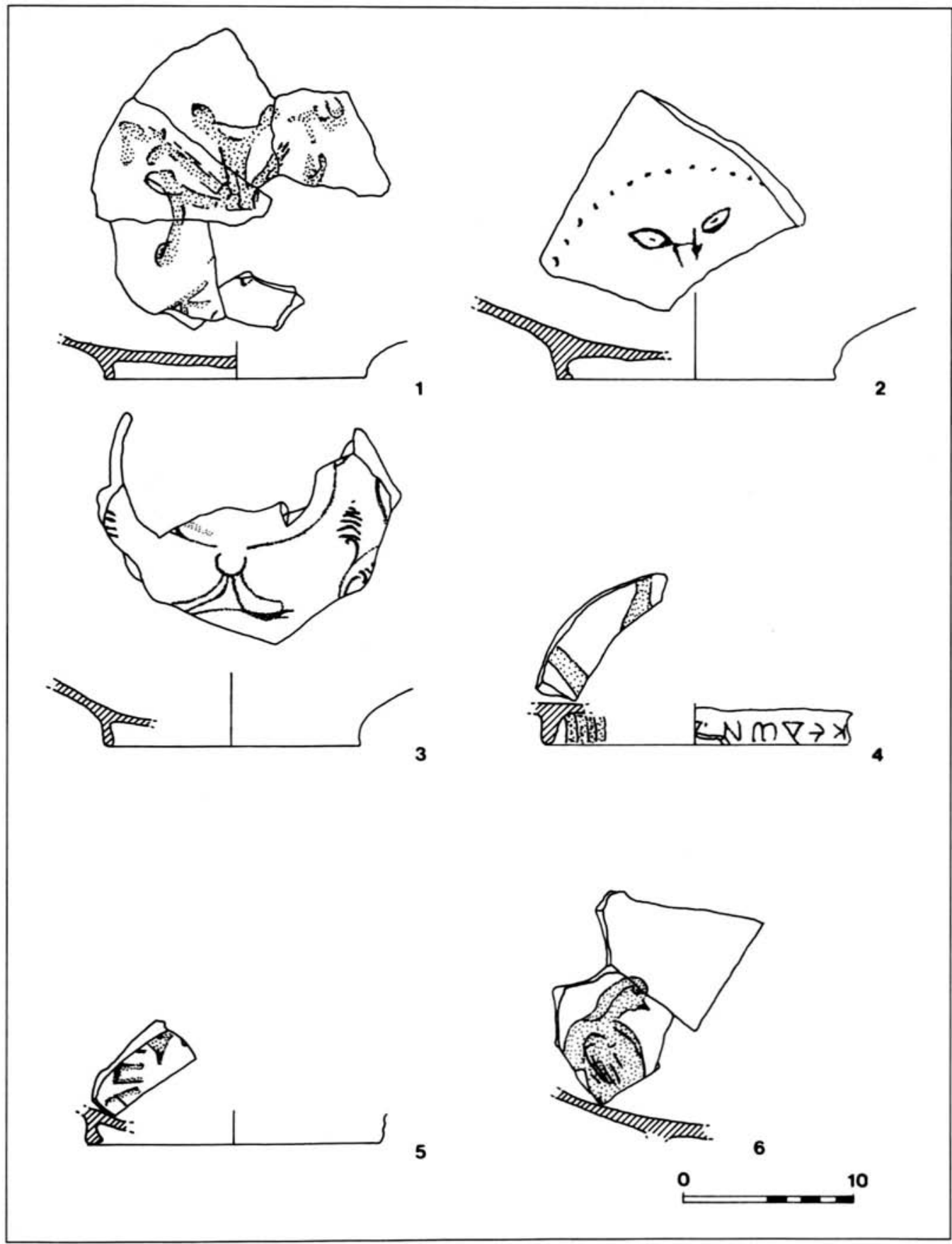

Figura 2. Platos de Gerasa del estilo I. 


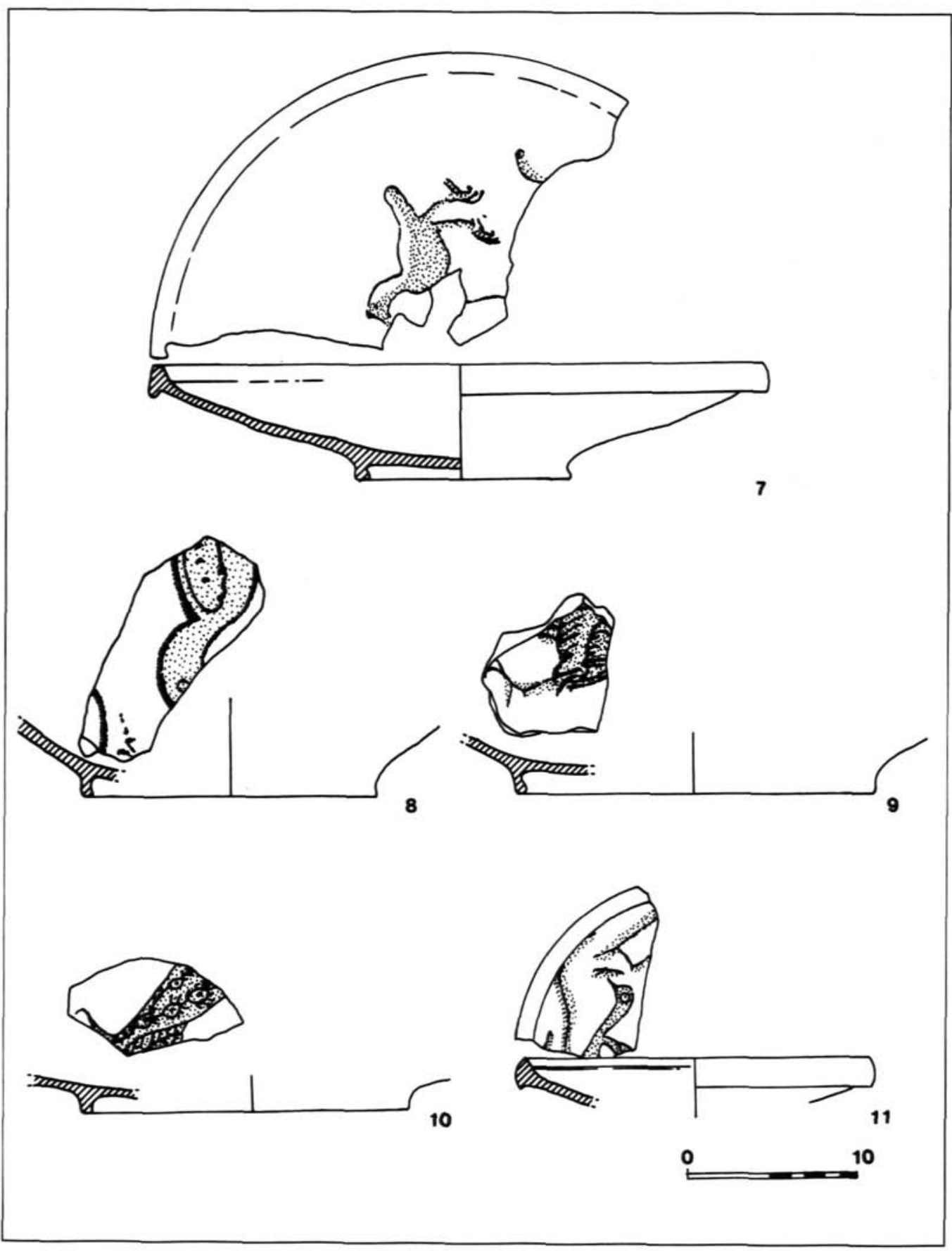

Figura 3. Platos de Gerasa del estilo I (7 y 9-11) y estilo III (8). 


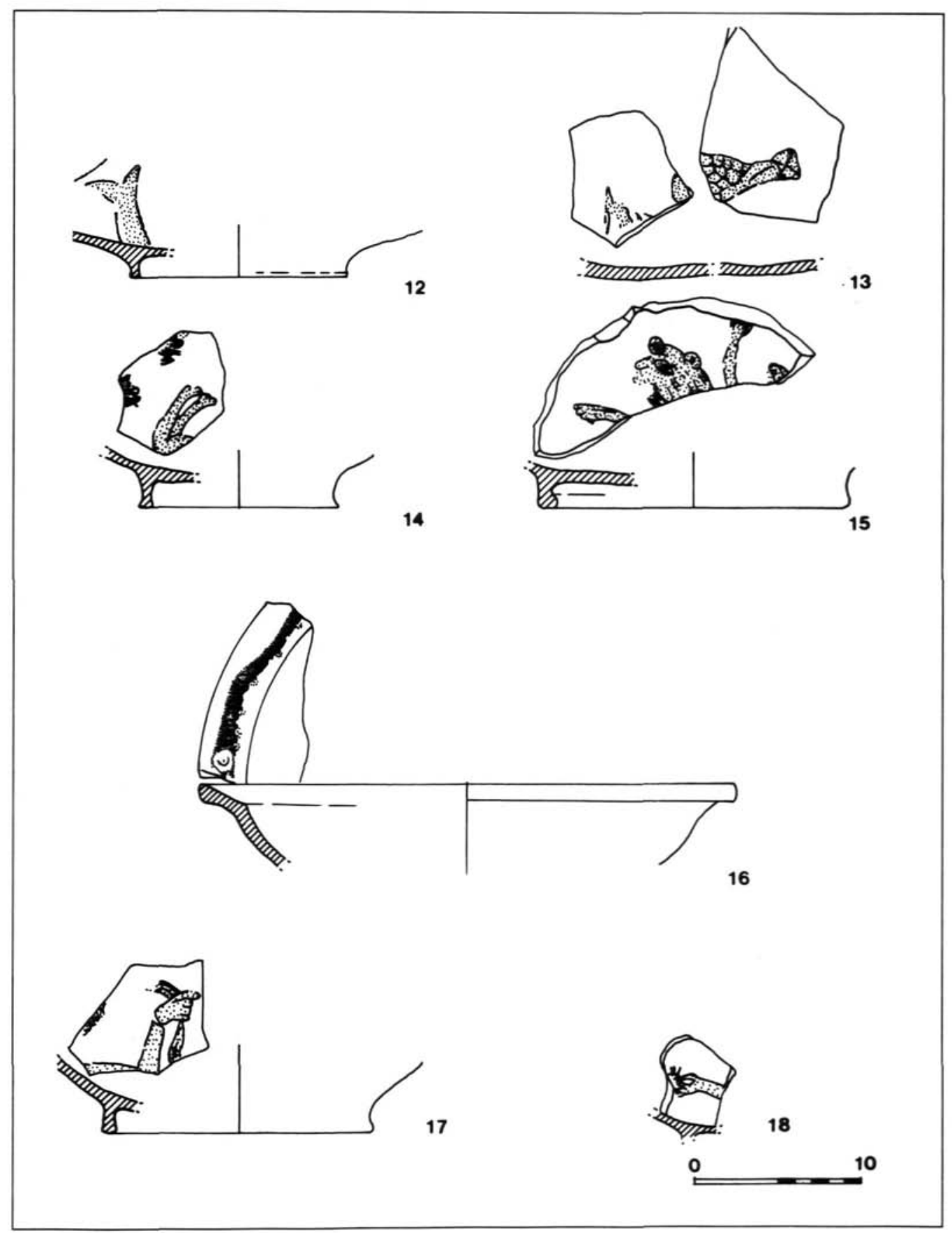

Figura 4. Platos de Gerasa del estilo I. 

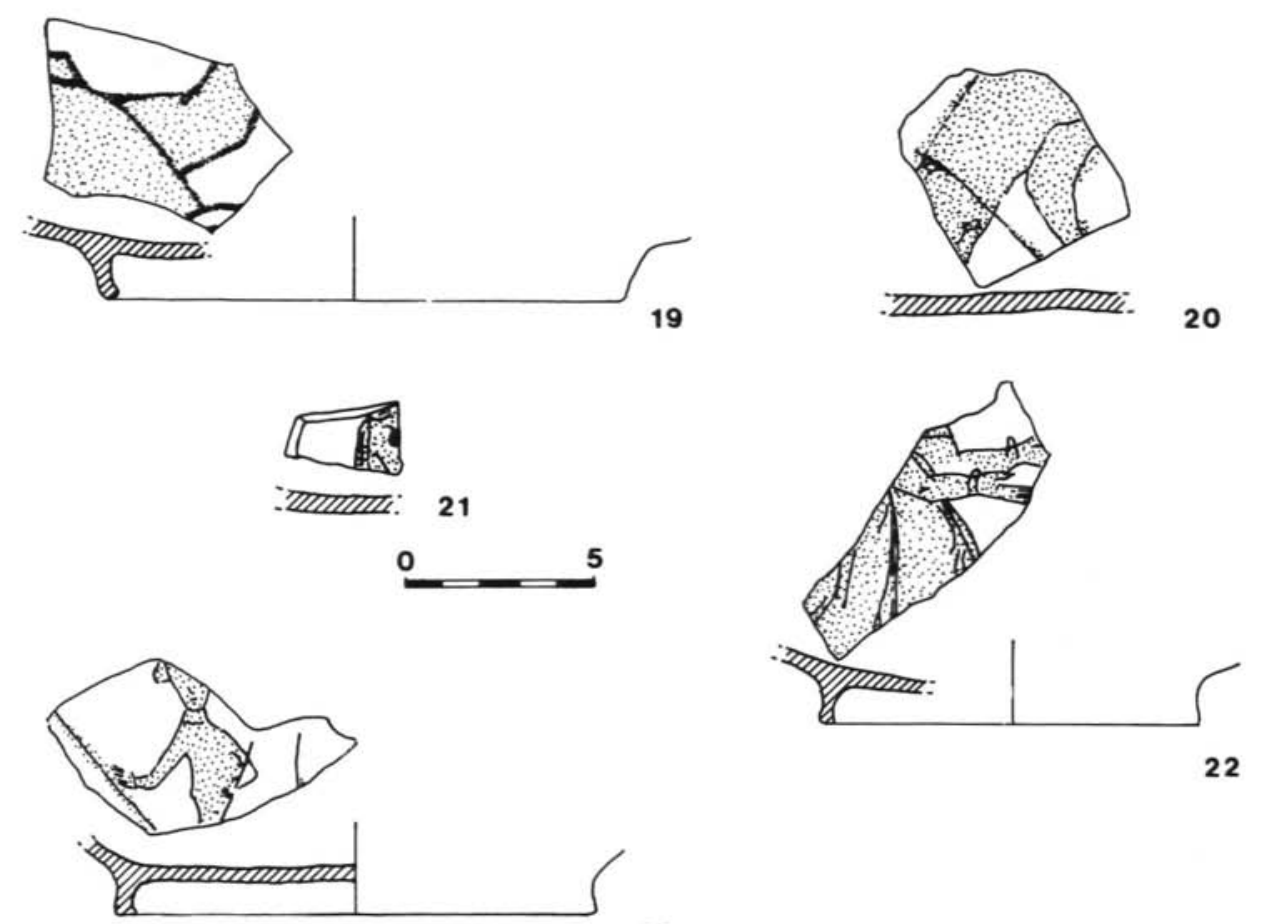

22

23
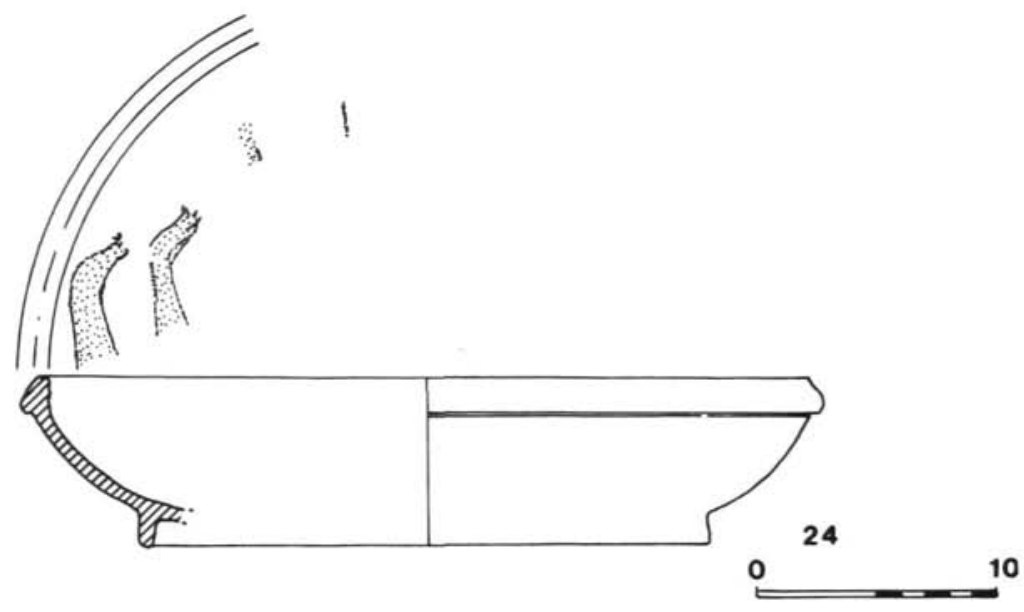

Figura 5. Platos de Gerasa del estilo I (20-24) y estilo III (19). 


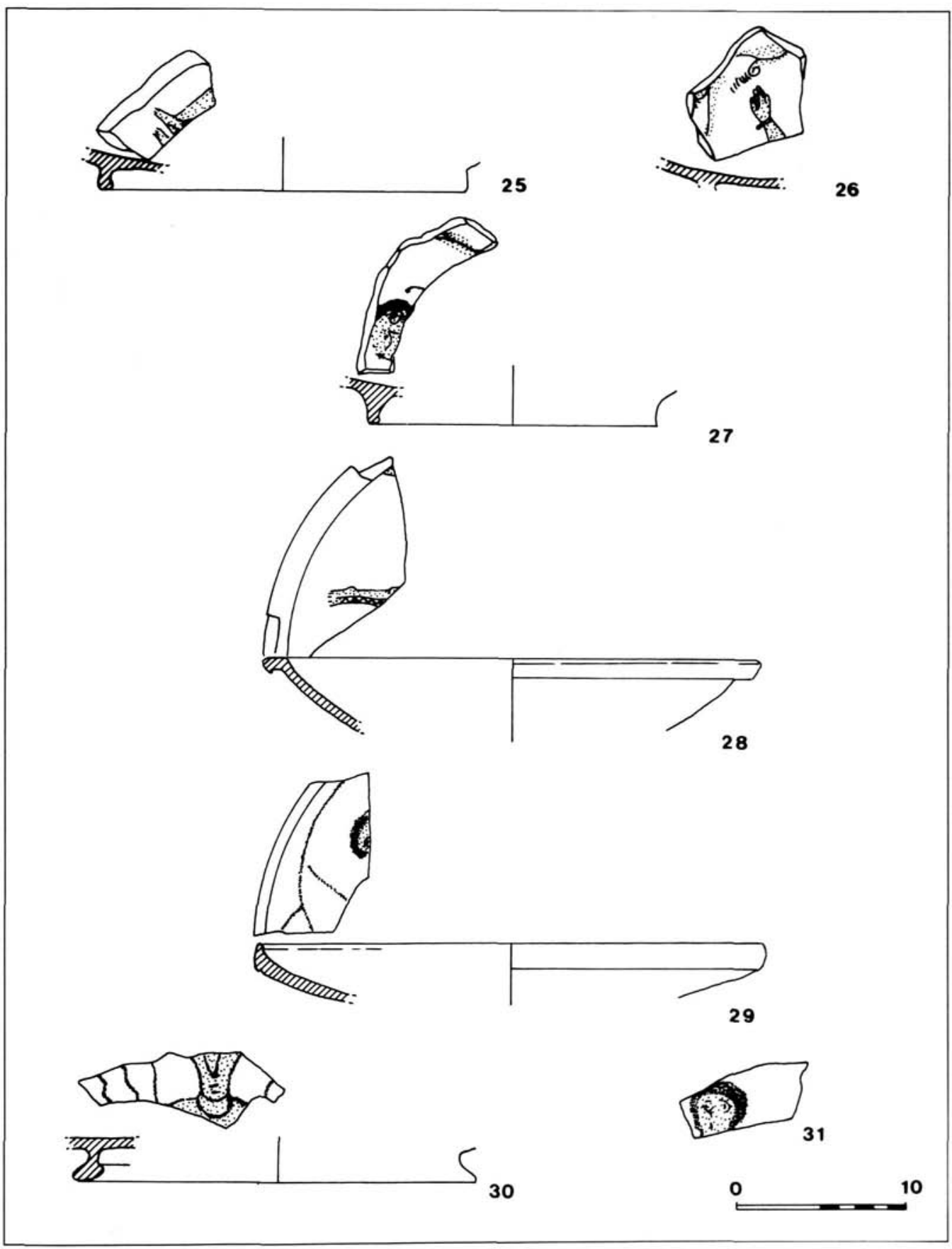

Figura 6. Platos de Gerasa del estilo I. 


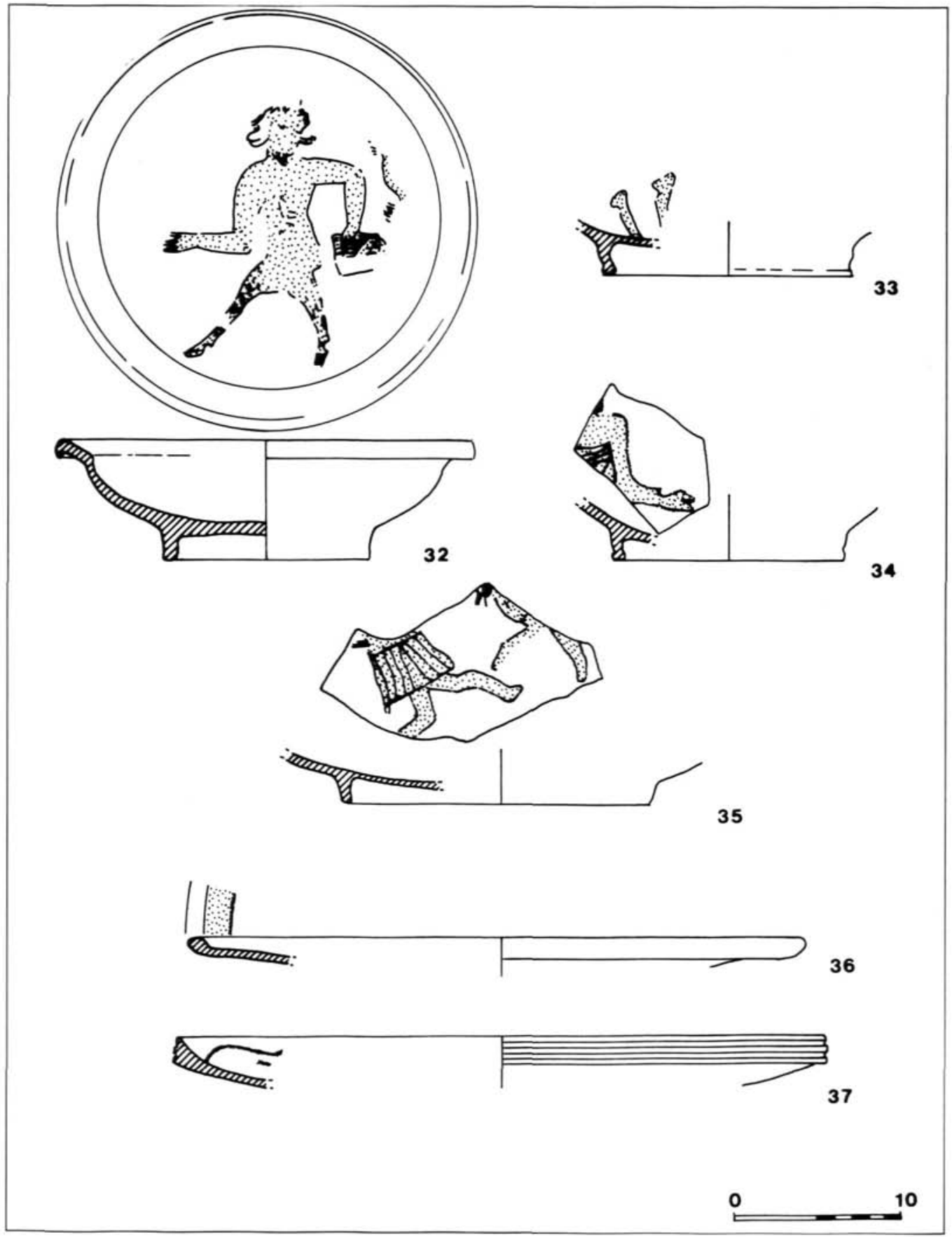

Figura 7. Platos de Gerasa del estilo I (32-33 y 36-37) y del estilo III (34-35). 


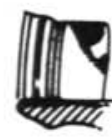

38

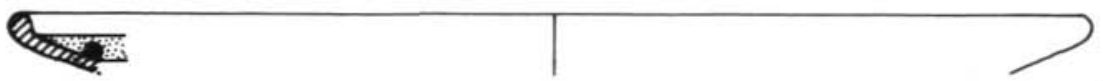

39
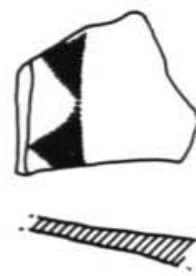

40
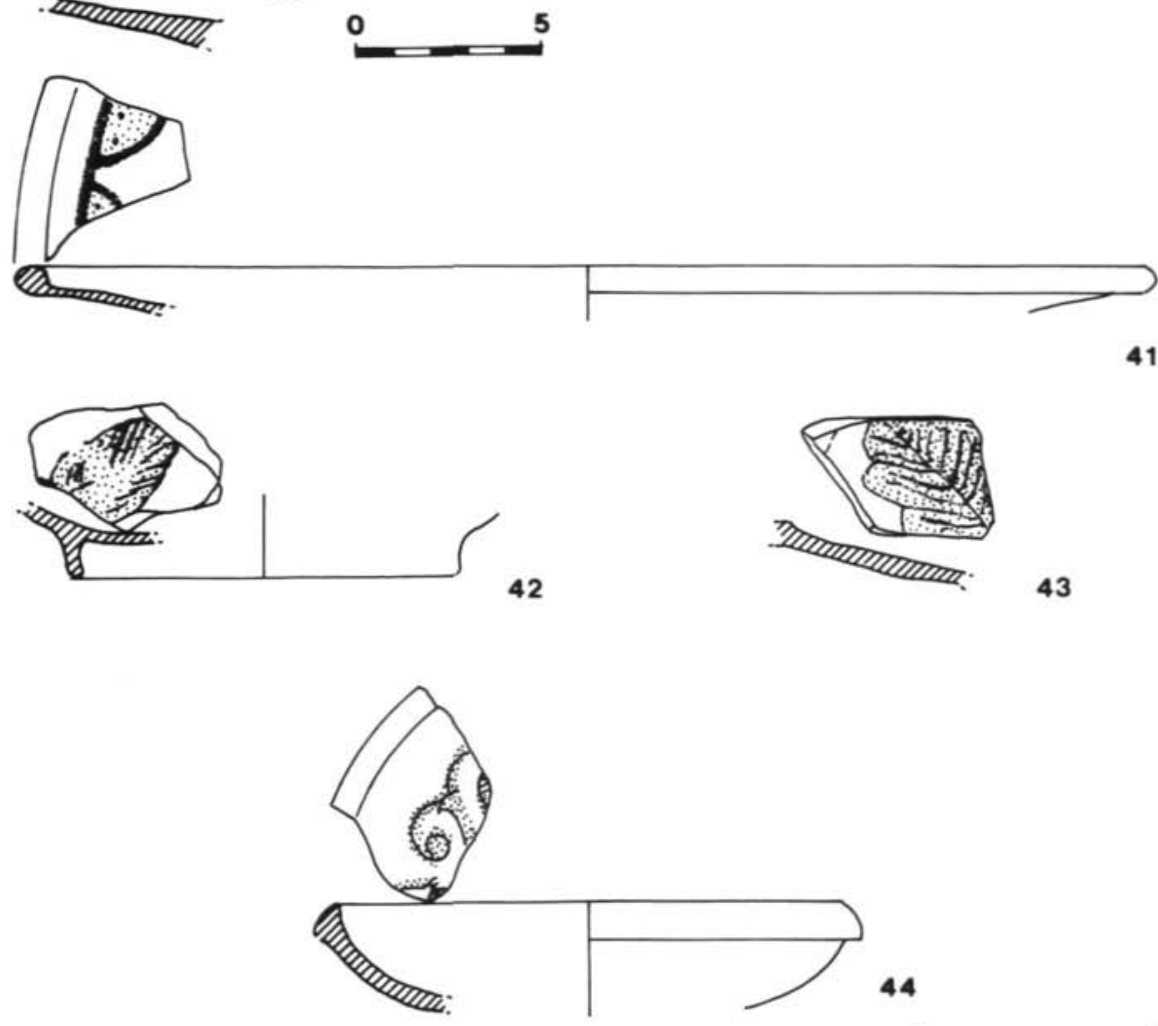

44

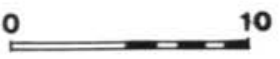

Figura 8. Platos de Gerasa del estilo I (38-43) y estilo II (44). 


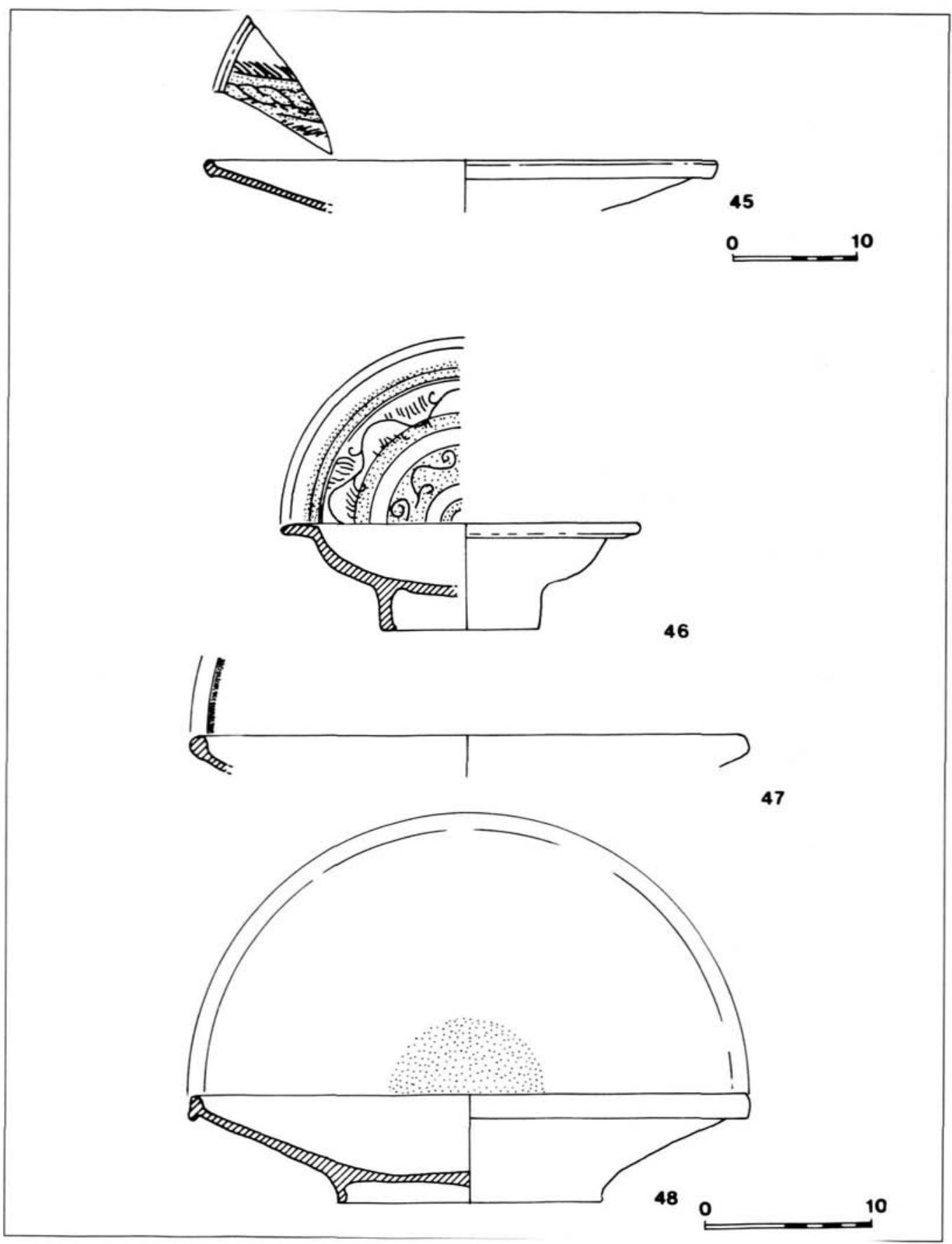

Figura 9. Platos de Gerasa del estilo I. 


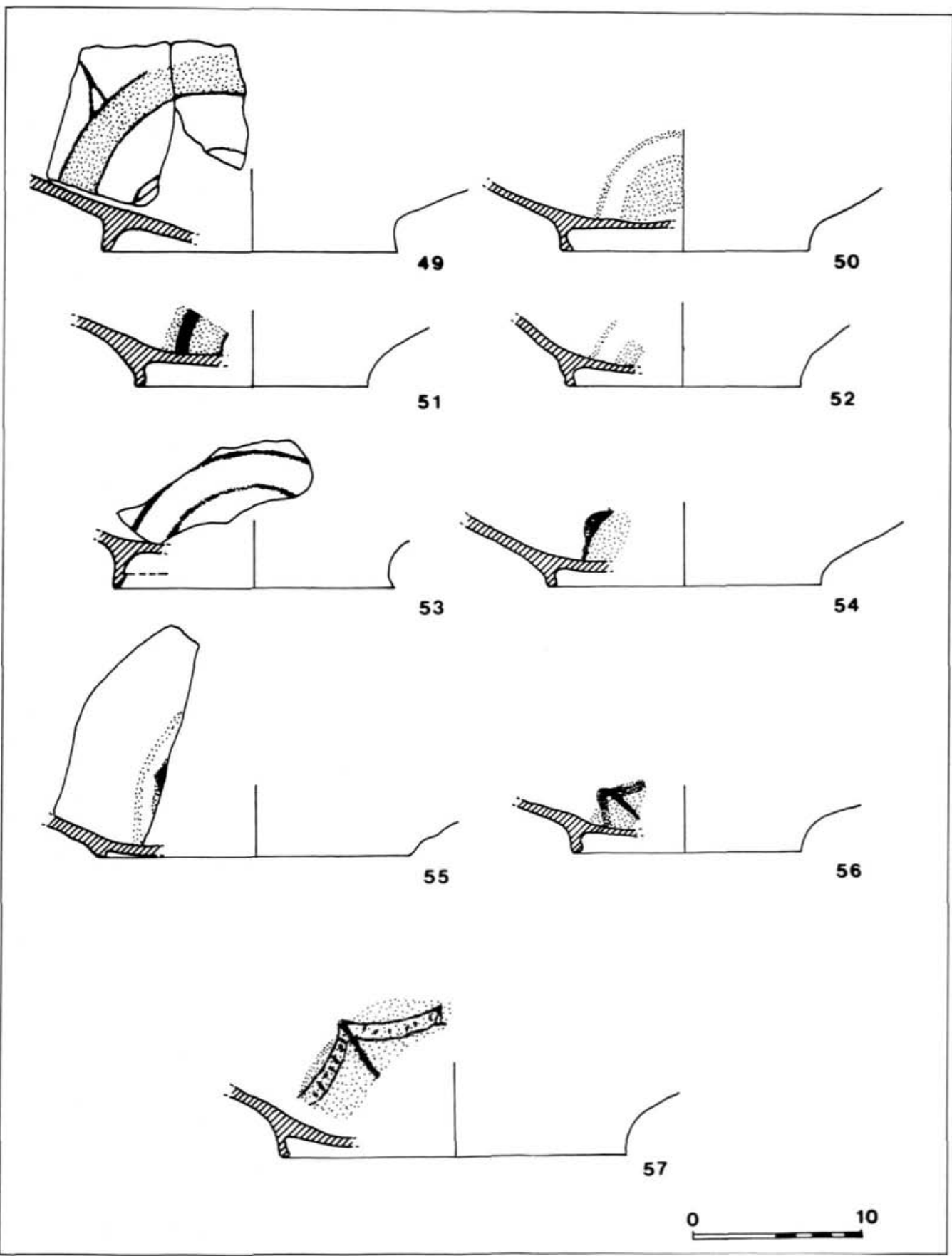

Figura 10. Platos de Gerasa del estilo I. 


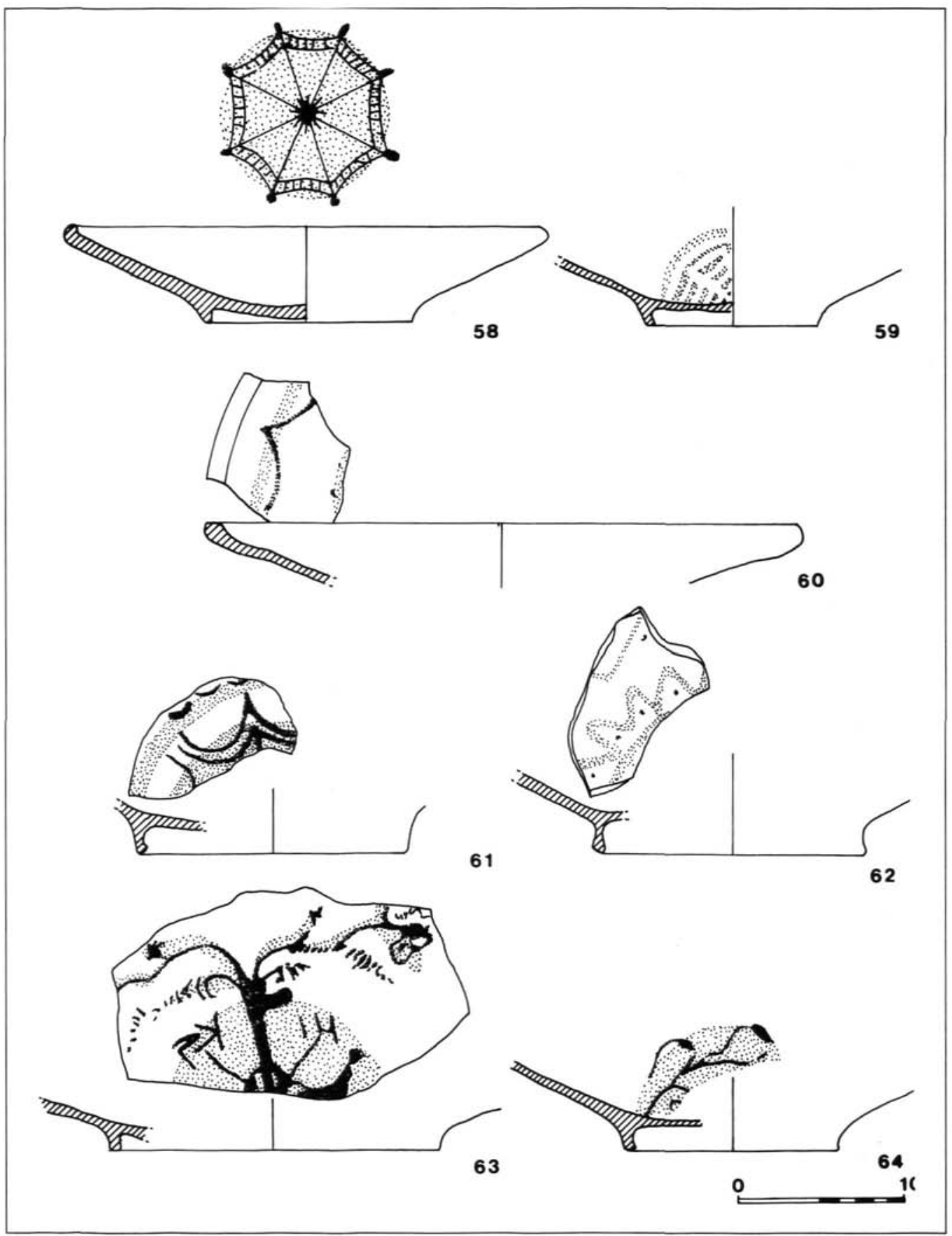

Figura 11. Platos de Gerasa del estilo I. 


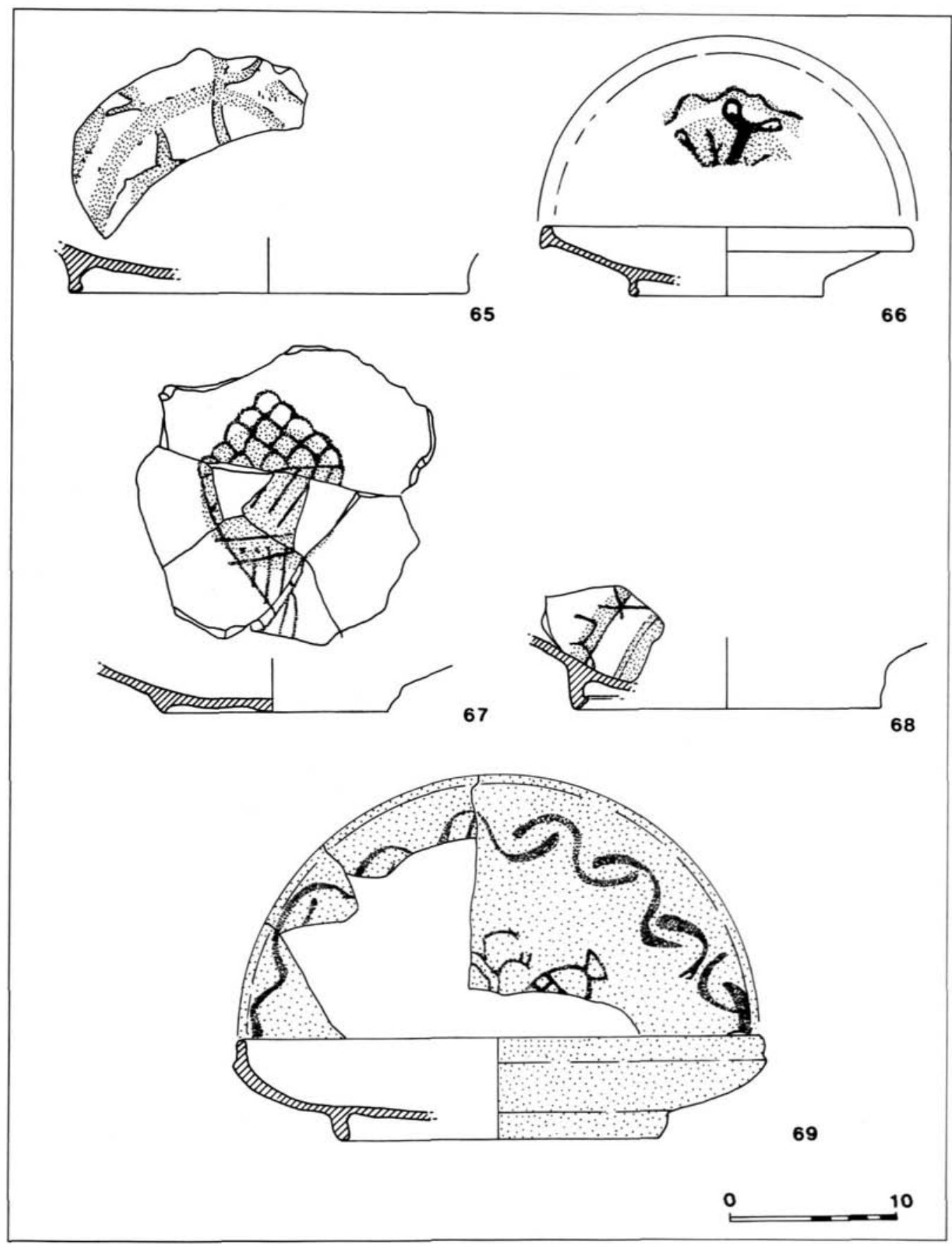

Figura 12. Platos de Gerasa del estilo I (65-68) y del estilo IV (69). 


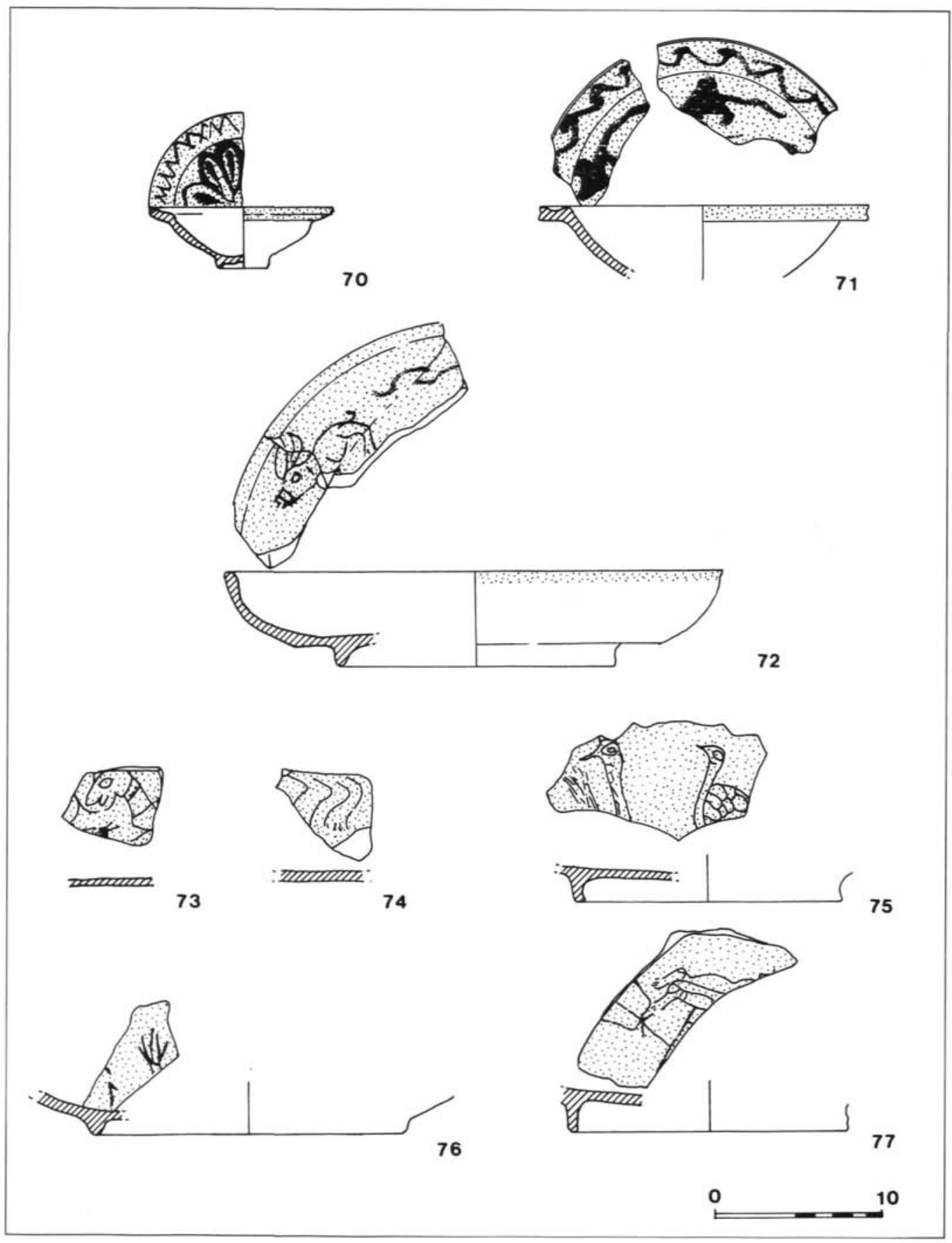

Figura 13. Platos de Gerasa del estilo IV (70-72 y 76), del estilo II (73-75) y del estilo I (77). 


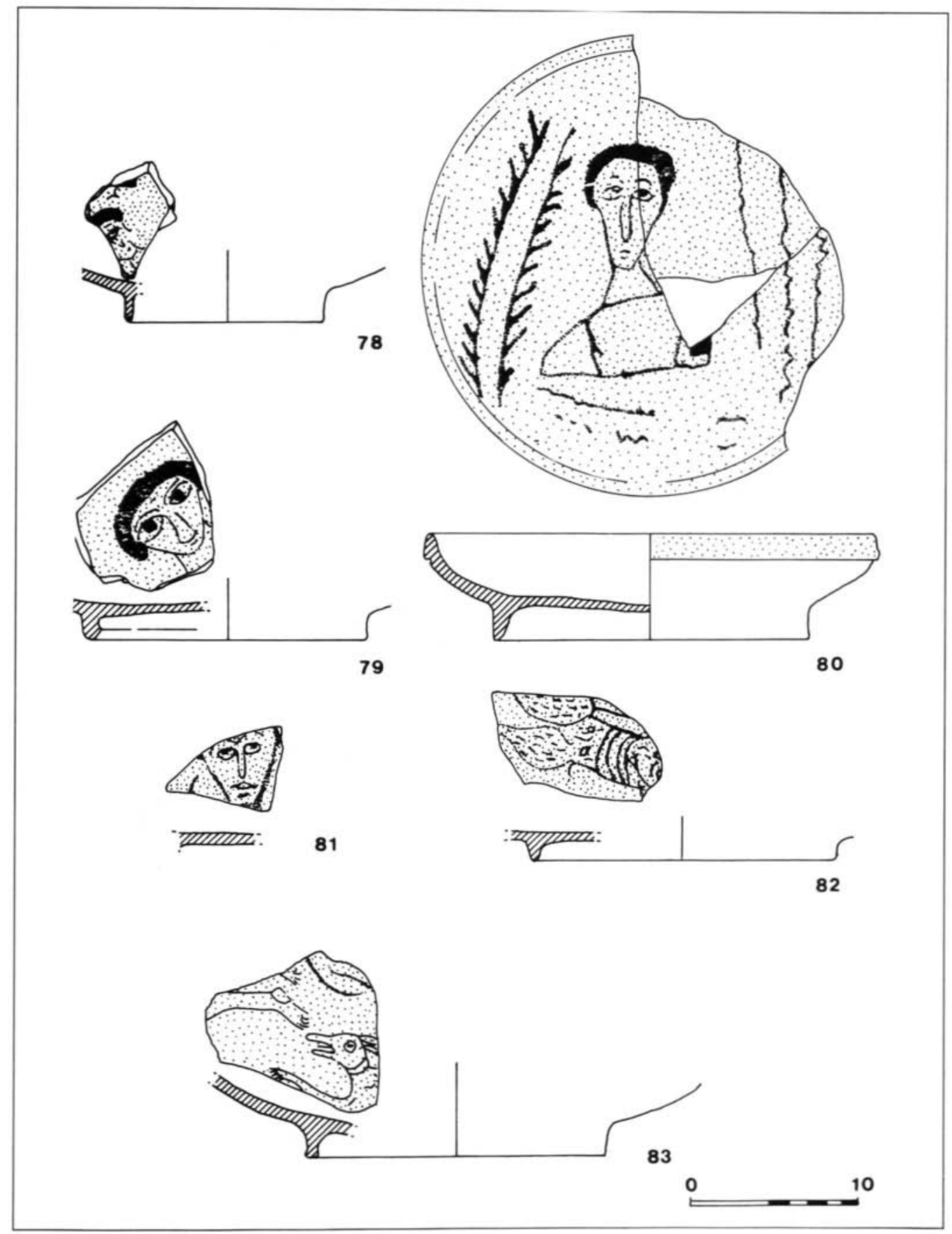

Figura 14. Platos de Gerasa del estilo IV (78-80 y 82), del estilo I (81) y del estilo II (83). 


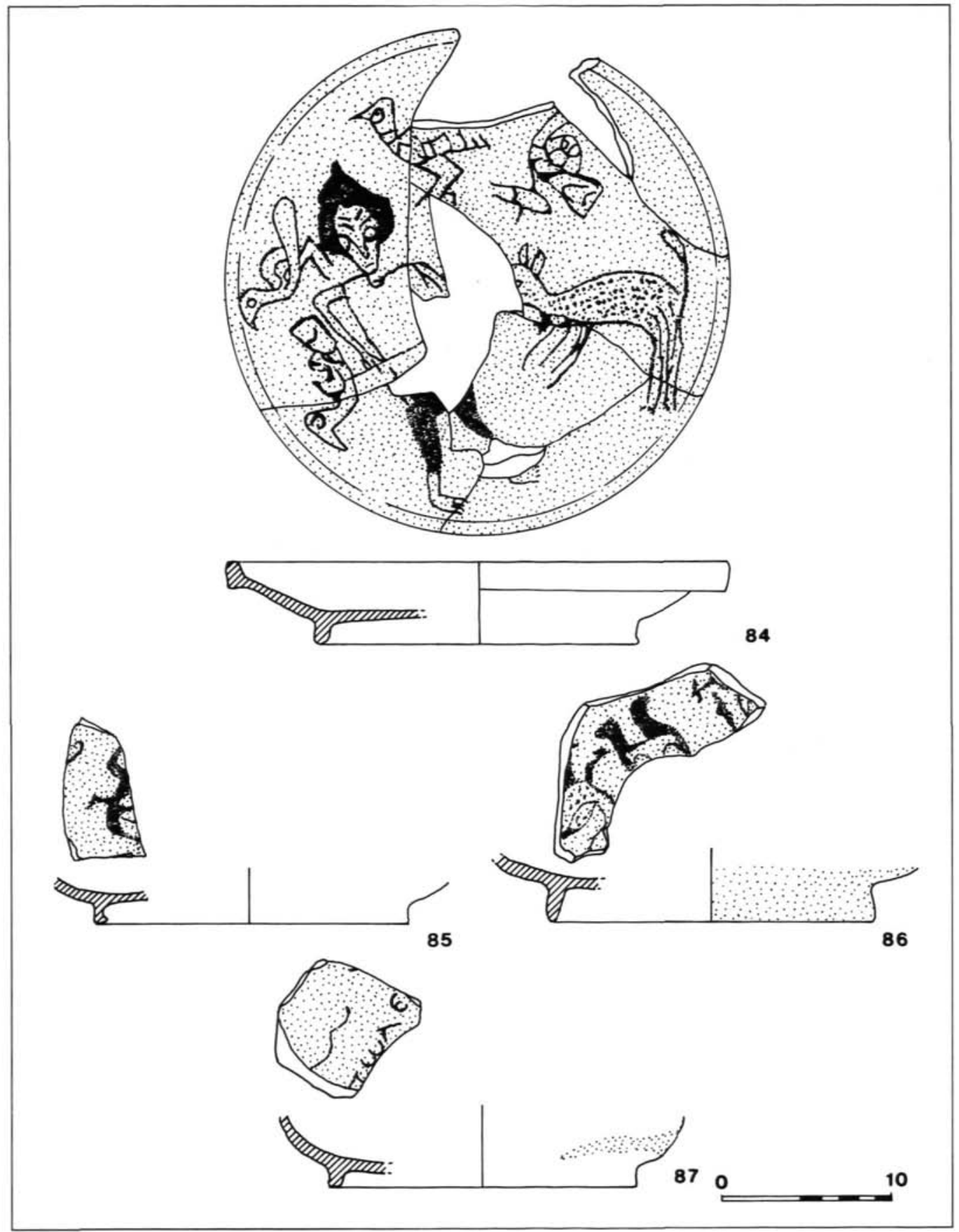

Figura 15. Platos de Gerasa del estilo IV. 


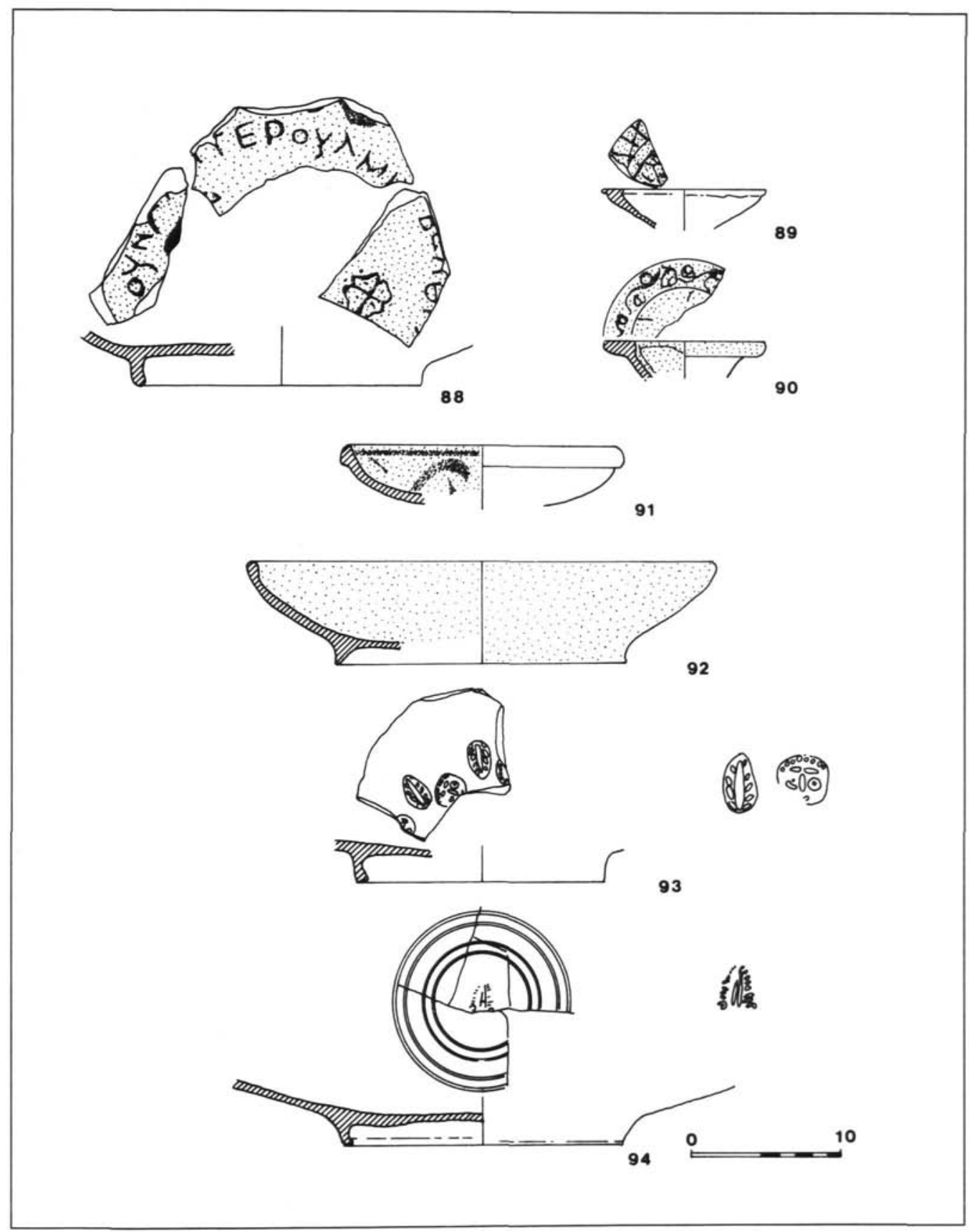

Figura 16. Platos de Gerasa del estilo IV (88-91), de engobe blanco (92), estampillados simples (93) y de círculos incisos con estampilla central (94). 

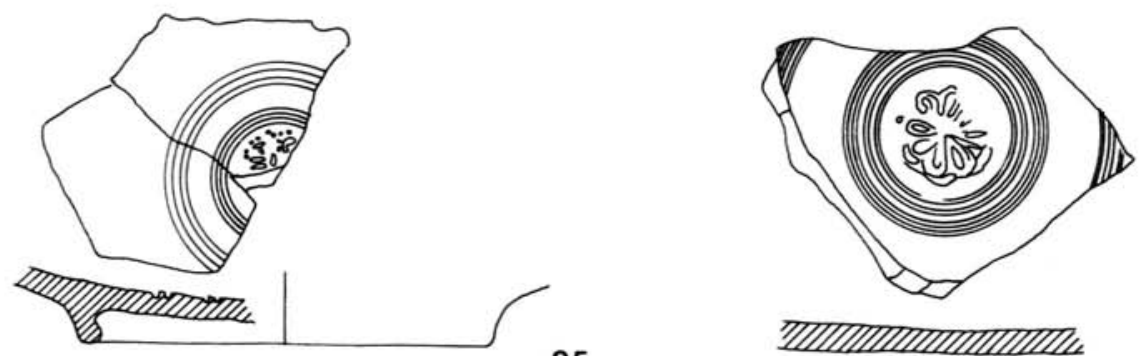

95

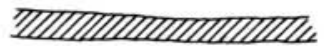

96
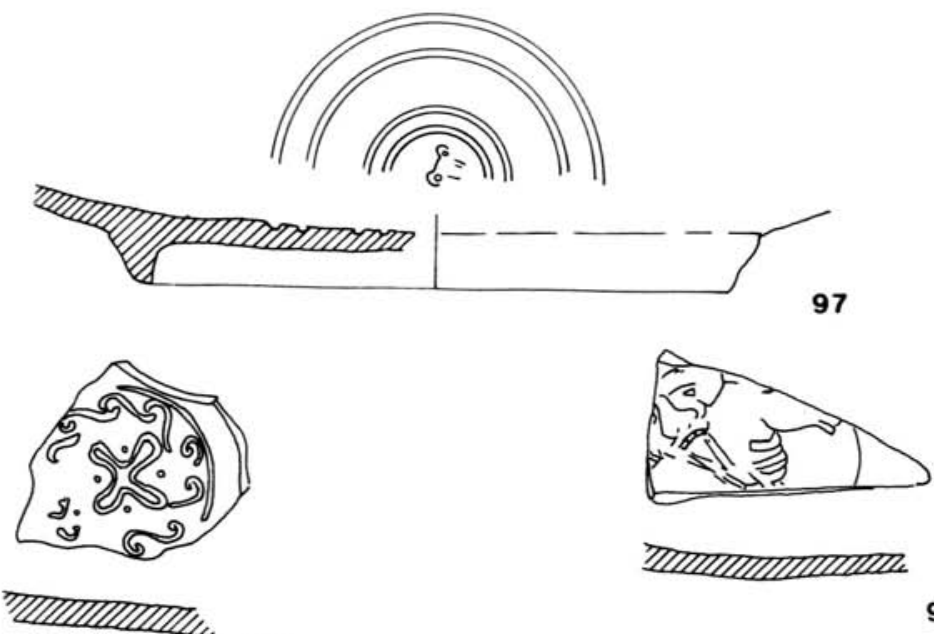

98
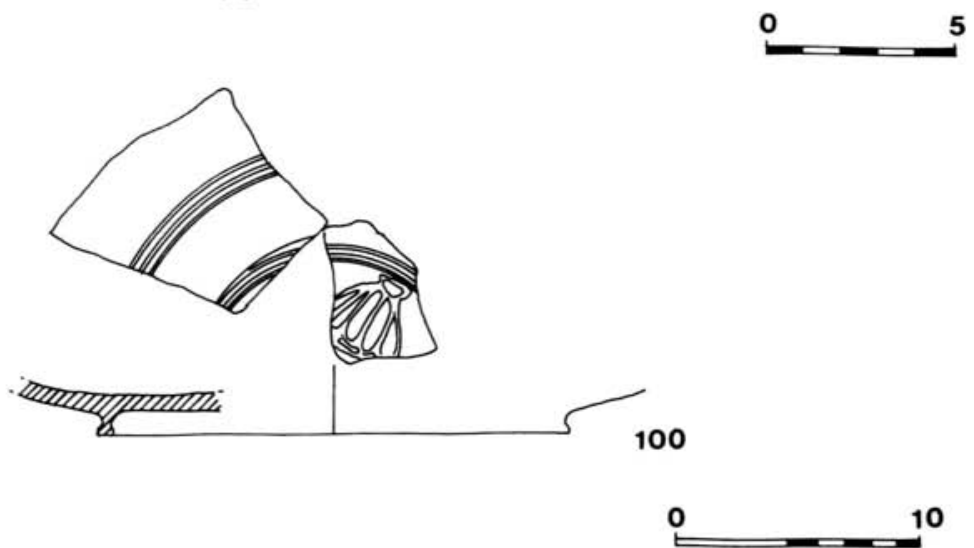

Figura 17. Platos de Gerasa con círculos incisos y estampilla central (95-97) e incisos (98-100). 


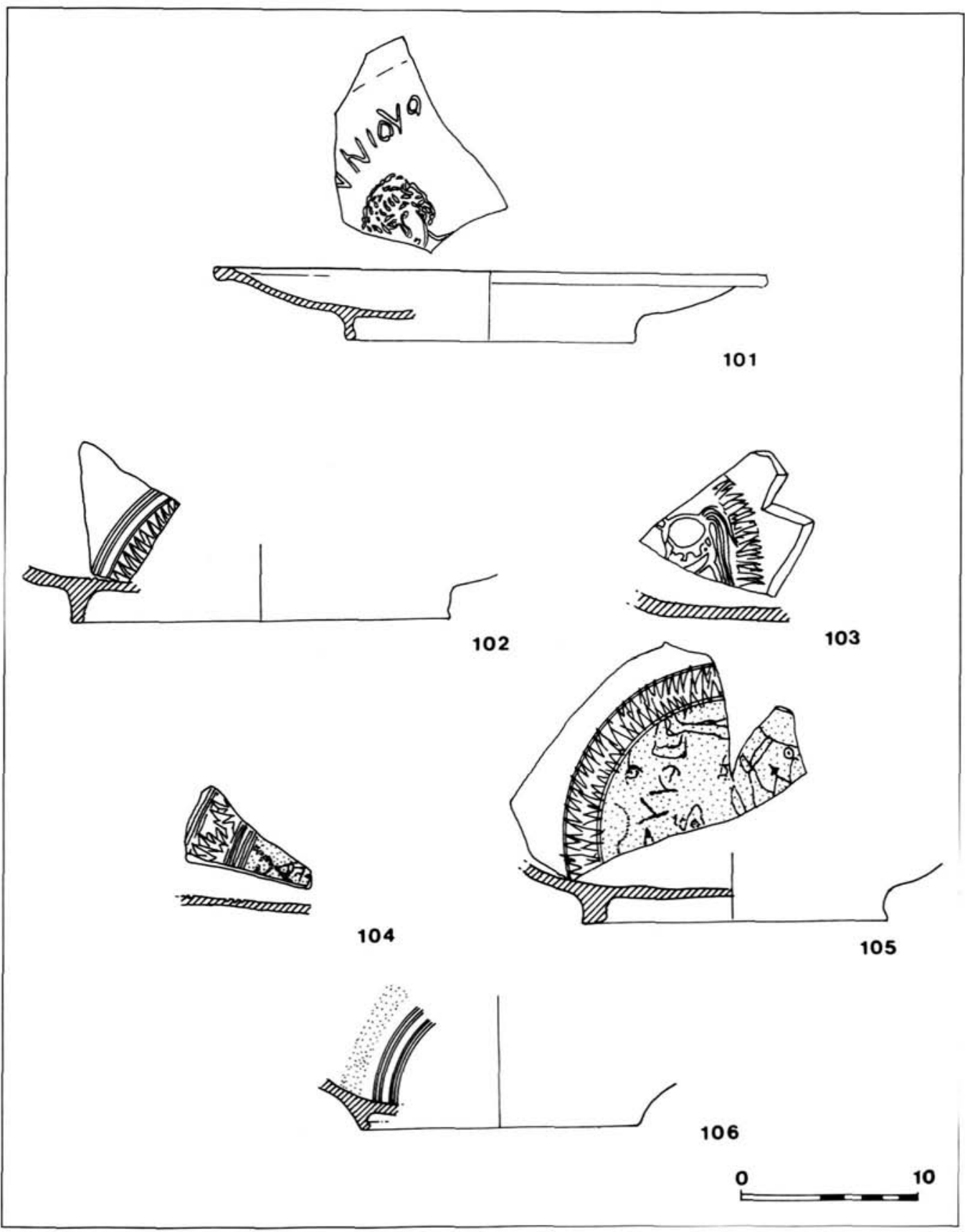

Figura 18. Platos de Gerasa incisos (101), incisos con impresión de ruedecilla (102-103), incisos, pintados e impresos a ruedecilla (104-105) y pintados e incisos (106). 